\title{
INCOME ASSESSMENT AND VFU GRADING
}

AFG/93/004 -- Integrated Livestock Programme 


\section{Interim Technical Report}

\section{Income Assessment and VFU Grading}

\section{Review and Preliminary Proposals}

April 1996

Kjell Öström 


\section{LIST OF CONTENTS}

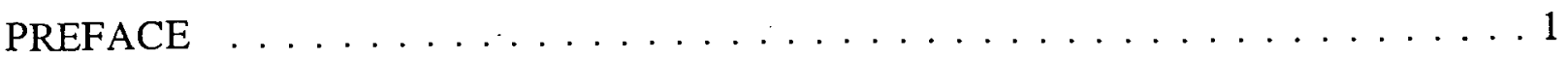

SUMMARY OF RECOMMENDATIONS $\ldots \ldots \ldots \ldots \ldots \ldots \ldots \ldots \ldots$

1. BACKGROUND $\ldots \ldots \ldots \ldots \ldots \ldots \ldots \ldots \ldots \ldots \ldots \ldots \ldots \ldots \ldots \ldots \ldots$

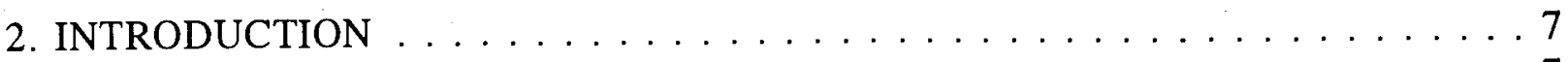

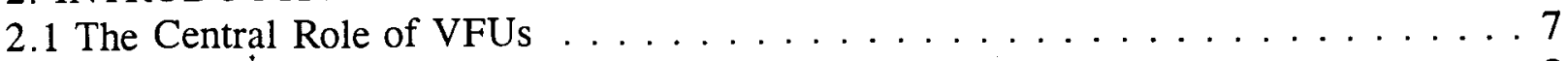

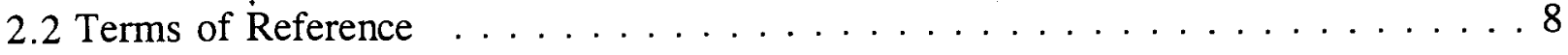

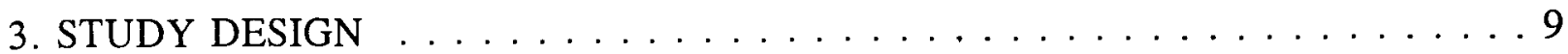

3.1 Civil War and Animal Health Services . . . . . . . . . . . . . 9

3.2 Animal Health Services - A Multi-Faceted Issue $\ldots \ldots \ldots \ldots$

3.3 Available Background Data . . . . . . . . . . . . . . . 11

3.4 Survey Design ....................... 11

4. MAIN FINDINGS AND CONCLUSIONS $\ldots \ldots \ldots \ldots \ldots \ldots \ldots$

4.1 Problems Encountered by VFU Staff $\ldots \ldots \ldots \ldots \ldots \ldots \ldots \ldots$

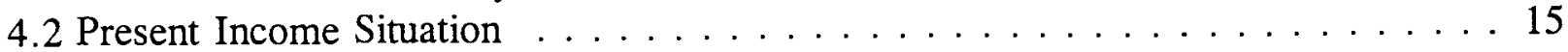

4.3 Minimum Income Levels . . . . . . . . . . . . . . . . . . . . 17

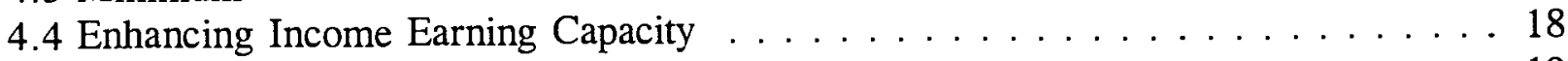

4.5 The Grading System . . . . . . . . . . . . . . . . . . . . . 19

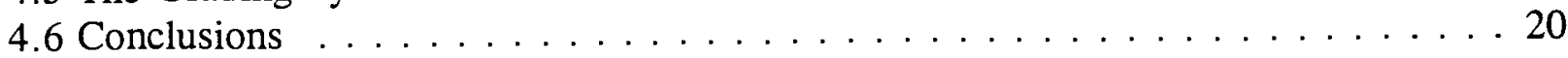

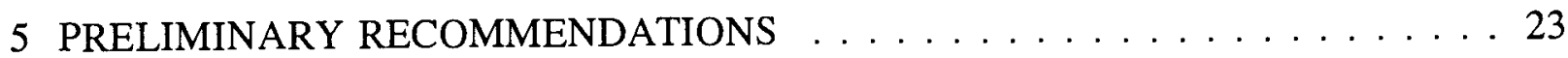

5.1 General Recommendations . . . . . . . . . . . . . . . . . . 23

5.2 Animal Health Expertise - Income Earning Capacity . . . . . . . . . . . 24

5.3 Attaining District Service Sustainability . . . . . . . . . . . . 25

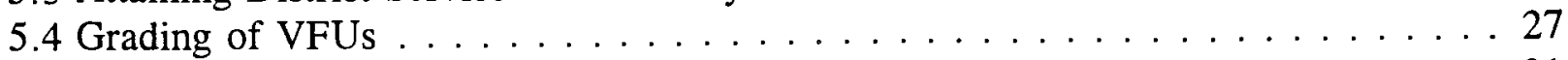

5.5 Design of Complementary Survey $1996 \ldots \ldots \ldots \ldots \ldots \ldots \ldots \ldots \ldots \ldots$

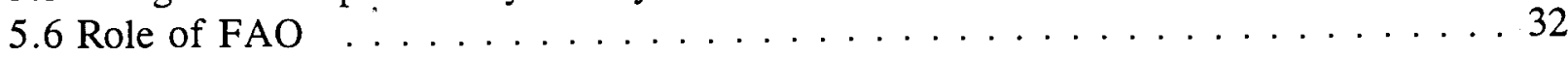

\section{$\underline{\text { ANNEXES }}$}

1. Terms of Reference . . . . . . . . . . . . . . . . . . 35

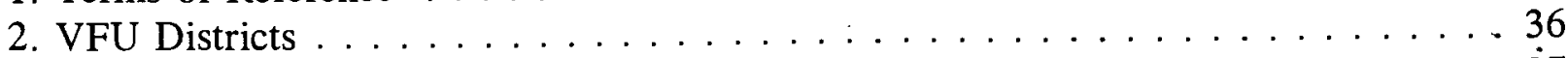

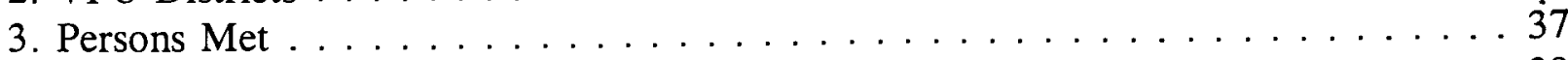

4. VFU Remuneration . . . . . . . . . . . . . . . . . . . 39

5. Test Questionnaire . . . . . . . . . . . . . . . . . . . 40

6. Average Monthly Incomes. Khost and Kandahar Regions . . . . . . . . . . . 41

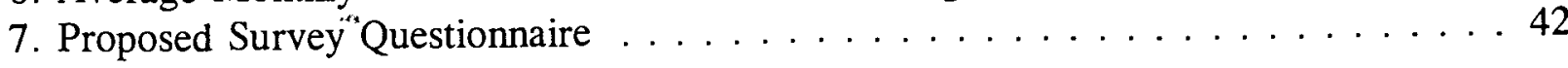




\section{PREFACE}

United Nations has through its different organisations and agencies, notably FAO been involved in supporting rural agriculture production in Afghanistan, in spite of very different conditions. Likewise, a large number of NGOs have over the years served as implementing agencies in the provision of animal health services. This symbiotic relationship has mostly been beneficial to the parties concerned, and served the overall aim of supporting the Afghan rural population in times of war and an ongoing civil war.

This Interim Report aims at collecting some preliminary data but also setting the stage for a comprehensive survey of incomes and other economic aspects in the 244 veterinary field units (VFU) set up by Implementing Partners (IP) in close collaboration with Afghan nationals and under FAO monitoring. Furthermore, it assesses the VFU grading system and touches upon the operations of eventually privatised VFU clinics, and the role of FAO.

Data collection will be undertaken, based on test surveys carried out during this first phase of the assignment. But as the future of the Project is now being assessed (AFG/93/004, AFG/94/002 Joint Midterm Project Evaluation Mission), a number of preliminary conclusions and recommendations will be presented, in spite of a lack of sufficient reliable information. Considering the general problem of data gathering and the volatile civil war situation in Afghanistan, it is imperative that a second phase of the Project allows for a high degree of flexibility, particularly as regards work of Project staff on regional level.

The work has been undertaken during the month of March, 1996, with two visits to Afghanistan. A first draft report has been commented on by Project Management and by Agricultural Operations Division and by Animal Production and Health Division, FAO Rome, motivating minor revisions.

The data and ideas gathered during meetings with more than a hundred veterinarians, paravets, management staff and others involved in the implementation of the Project proved invaluable, and for which I am most indebted. Furthermore, discussions with the Afghan Coordination Body for Afghan Relief (ACBAR) and a number of IP representatives, in Peshawar and elsewhere was most useful. This report proposes a survey to be undertaken by the Project Management in cooperation with ACBAR.

Without the very positive contribution by Project Management during the first phase of the assignment not much could have been achieved, considering the cumbersome logistical problems of the task. When the raw data of the second phase survey in a few months time is available, a thorough analysis and more detailed recommendations will be presented.

Rome, April 2, 1996

Kjell Öström 


\section{SUMMARY OF RECOMMENDATIONS}

The first mission, March 1996 has yielded valuable information pertaining to the VFU staff situation, both as regards problems and short and medium term possibilities. Extensive discussions have been held with Project Management staff, representatives of UN agencies, European Union and NGOs and two field tours with visits to VFUs have been undertaken.

Participation in two regional workshops arranged by the Project gave the opportunity to conduct interviews and a survey; some one hundred VFU staff filled in a questionnaire and the answers have been compiled and analyzed (see Chapter 4). Based on those and other findings as well as available written documentation, some preliminary recommendations are presented in Chapter 5.

From an assessment of the Programme in general it seems, as if the activities are well under way as regards establishing of VFUs, cooperation and coordination of work with implementing partners (IP) as well as disbursement of equipment, stationary and funds, and administrative reporting in general. The uncertainty pertaining to support of medicines through donor agencies, e.g. the European Union is causing some uneasiness amongst VFU staff. Also, the uncertainty as regards a prolongation of the Programme as from 1997 is a concern, and accentuates the need for an orderly phased privatisation of the clinics.

What seems to be problematic to Programme and IP staff because of a very difficult communication situation is the monitoring and technical support as well as provision of medicines and other supplies directly related to VFU work.

It seems, as if the Programme has been able to secure competent and dedicated management staff and other key personnel. On the other hand, this staff is thinly stretched over a large geographical area, and engaged in a vast number of practical issues. Thus, the direct monitoring of VFUs in the field suffers, also because the travelling is slow and sometime problematic from a security point of view.

It is assumed, that only a limited number of the VFU clinics would survive if Programme and IP support would be totally cut out during 1996. It is assumed, however, that the Programme is extended, and there is scope for a controlled test of VFU staff interest in taking over their clinics during the next two years.

Based on a preliminary assessment of available data and opinions expressed by IPs, donor agencies and Programme staff, it is recommended that: 
- the Programme is financed for another 3 years, and during 1997 properly establishes the local animal health services through VFUs as a responsibility of the involved veterinary staff through a phased privatisation of the clinics. The emerging regional Veterinary Associations as well as ACBAR are consulted and District Shuras are kept well informed;

- the regional animal health service competence is strengthened through additional Programme monitor staff capacity, working closely with IPs and other NGOs, by way of professional support and coaching of VFUs. Coordination is secured through regional Veterinary Committees and the cooperation with the regional Veterinary Associations is sought;

- FAO prepares the strengthening of national animal health monitoring competence by data collection and compilation, medium and long term assessment of the animal health situation and planning of vaccination campaigns, etc. Consent is sought with Government agencies and the Veterinary Associations;

- the existing grading system has served the initial purpose of establishing a network of VFUs and should not be changed till commencement of the second phase of the Programme, e.g. 1997, and then be based on a definition of the general public need for animal health services and demand of the local livestock owners. Criteria for such a revised robust grading system will be further discussed;

- FAO should, by way of soft loans assist key staff in strategic clinics, primarily in the 16 grade IV VFUs to procure the clinic, setting the goal of contracting ten of them to undertake general and specific veterinary services and in cooperation with NGOs undertake capacity building, monitoring and coaching of them, using regional office staff and initiators;

- it is tentatively proposed, that FAO assesses the possibility of providing an interest-free soft loan (written off over three years) to key VFU staff covering the cost of taking over the clinic. The staff will no longer be employed by IPs (or FAO), but be self-employed and work in cooperation with the self-employed BVWs;

- the VFUs should be encouraged to assess, if VFU service areas should be based on districts or if more practical cost-saving arrangements including VFU cooperation related to the planning of their work should be considered;

- as there will be increasing pressure on Programme staff and Management to actively assist the clinics in the field the administrative routines pertaining to reporting to FAO HQ, etc. should be simplified and administrative work be cut back, allowing also for more time for planning animal health services in the long term perspective on the regional level; 
- the emerging regional Veterinary Associations should be actively supported on matters related to importation of medicines and vaccines, establishing a Code of Conduct, their own as well as the VFUs' role in the privatisation process and in the organisation of a future Government veterinary service in Afghanistan; and

- the FAO is presently in many ways serving as a government agency in the field and this motivates a strengthening of the Programme monitoring capacity on the regional level. Likewise, the professional advice as regards imports of medicines and vaccines and their quality assurance, is a crucial role for the Programme Management, the regional Veterinary Committees, representing Government, donor agencies and the animal health expertise could play a crucial role also in this field. 


\section{BACKGROUND}

Afghanistan was long considered one of the world's least developed countries, but in 1978 it was poised on the brink of a new age. For the first time since the turn of the century it had become self-sufficient in grain production. Traditional farming systems .were served by government training institutions, departments and offices. But ten years later, agricultural production systems had been devastated. ${ }^{1}$

It is estimated, that at least $85 \%$ of Afghanistan pre-war population were directly reliant on agriculture, and it is estimated that in 1988 general agriculture production was only about half of pre-war levels. Virtually no services or supplies were available to farmers, and animal diseases were given as the major constraint to the recovery and restoration of the livestock sector. $^{2}$

The livestock sector has, however, shown remarkable resilience, but sheep and goat numbers were in 1994.thought to be less than half pre-war levels, except in the northern provinces. Reduced animal numbers and the disruption of access and the movements of traditional nomadic flocks and herds improved the status of natural pastures. ${ }^{3}$

Most farmers in Afghanistan understand that many factors govern the productivity of livestock: animal health and disease control, management, nutrition and breeding. There is, however, little reliable information or data on the incidence or economic effects of animal disease in the country. While there is also a limited knowledge about the animal feed situation, there has newer been any question about the need for animal health services. ${ }^{4}$

From the early 1980's onward, UNDP/FAO maintained an involvement in the agricultural sector, implementing projects under extremely difficult war conditions. As from 1989 onwards agricultural activities increased considerably, carried out through projects executed by FAO and UNDP/OPS, as well as a number of NGOs. By 1994, at least 160 NGOs and PVOs were registered with ACBAR. ${ }^{5}$

Since 1989, the UNDP supported two livestock health and disease control projects, i.e. the southern veterinary component of the OPS, relying heavily on NGOs as Implementing Partners (IP) and the FAO executed northern veterinary clinic project. There was little fundamental difference between the two projects in terms of basic philosophy - both aimed at developing a sustainable and self-supporting system of privatised animal health care at the district level. 6

The idea of establishing Veterinary Field Units (VFU) was born during implementation by NGOs of the southern project, and in 1994 there existed VFUs and their supporting Basic Veterinary Workers (BVW) in some 170 districts in southern Afghanistan. It was then

\footnotetext{
${ }^{1}$ Project Document AFG/93/004,p 1
}

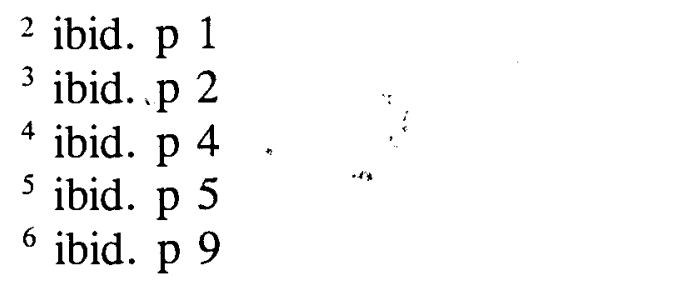


concluded that it made little sense to continue two separate livestock health projects in Afghanistan and a single unified livestock health and production programme based on the concepts developed by the southern project, into which the various useful elements of the northern project was merged. 7

7 ibid. p 13 


\section{INTRODUCTION}

The Project Document of December 1994 states that the entire animal health and production support service has been severely weakened as a result of war. It further concludes, that the UNDP supported projects have developed a unique network of basic animal health service utilising the services and skills of implementing partners. This network will result in a selfsustaining district level animal health service but requires an additional period of support. Once basic animal health cover has been provided, the next step is to restore other production elements, based on the identification of major production constraints.

A unique feature of the programme is the direct support of the smallholder farming communities and the programme provides training opportunities for rural women. The programme planned for 30 months is funded from UNDP IPF funds (USD 5,5 million), which are mainly used to support essential ongoing elements of the animal health component. Cost sharing is also envisaged as other donors, notably European Union, have shown an interest in support (vaccines) for the sector.

\subsection{The Central Role of VFUs}

The overall development objective of the project is to restore and improve the productive capacity of the national livestock composite owned by smallholder farmers and nomadic and semi-nomadic pastoralists. The means is the creation of a sustainable system of delivering basic animal health care where district level services are directly paid for and supported by livestock owners, the free market supply of remedies and vaccines, establishing the interface between the privatised and eventual state veterinary services and by initiating the rehabilitation of livestock production systems. ${ }^{1}$

A simplified method of lump-sum payments to IPs for each VFU to be established was introduced. The system allows IPs to staff VFUs with veterinarians, paravets, vaccinators and BVWs on a district-by district basis according to geography, accessibility of livestock owners, and numbers of livestock. Three categories of VFUs was (in 1994) envisaged in the Project Document: ${ }^{8}$

- VFUs qualifying for a start-up grant during first year of USD 9000

- VFUs on a support grant for a period of 1 - 2 years of USD 7000

- VFUs on a maintenance grant of USD 4500

During 1995, the system was changed into four grades (Annex 4) and classification of VFUs are now based on factors that reflect sustainability such as:

- proximity to high priced markets

- number of animals related to catchment area

- vets/paravets working out of their home village, district

- competence of vet personnel

- proximity to supplies of medicines

- willingness and ability of farmers to pay for services.

${ }^{8}$ ibid. p 33 
Grade I need higher and longer support than Grade II-IV VFUs, which are expected to become sustainable sooner than the first category. Salaries and public service remuneration paid by IPs to veterinarians, assistant vets and paravets in Grade I is typically two or three times higher than in e.g. Grade II and IV. A vet in Grade I can expect a total monthly salary of Rs. 4000 , in Grade III Rs. 2500 and in Grade IV Rs. 1500 as a public service remuneration. A paravet in those grades can expect Rs. 2 500, Rs. 1600 and Rs. 1500 respectively. ${ }^{9}$ As a complement, staff are now expected to charge customers for their services, and the full cost of medicines, to support their income.

A main feature of the project design is sustainability of animal health services, to be achieved under extremely difficult conditions because of a civil war situation. And as there is during the project period, no central government in control of the whole country, such services have to be provided by way of private individuals. NGOs and international development organisations are there to support such a venture, but only the national expertise veterinarians, paravets, assistant vets and BVWs - are in a position to undertake the day to day tasks. The two crucial issues thus emerging are:

- what is the income earning capacity of the national experts in clinics? Of BVWs?

- to what extent and how long should the VFUs be assisted, i.e. how should a grading system be devised?

\subsection{Terms of Reference}

This short term consultancy study in two phases aims at answering these questions. The Terms of Reference for the first mission states, that the following tasks shall be undertaken (see also Annex 1):

- review programme activities

- review evaluation report and incomes of VFUs

- design a survey to collect relevant income data

- field test survey and train staff

- prepare brief interim report and consultancy report.

Discussions at FAO in Rome have indicated that it is of value if the views of the IPs, i.e. a number of NGOs, can be consulted during the study. Furthermore, results in the form of data and also preliminary conclusions and proposals from the first mission should be made available to the evaluation mission due by the end of March. Those two aspects have been taken into account when planning the work and designing a survey.

A joint interpretation of Terms of Reference at FAO HQ led to the following prioritization of work during the first mission:

${ }^{9}$ see Annex 4 
- safeguard the cooperation of the IPs as regards data collection

- overall assessment of the VFU staff income earning situation

- establishing of a methodology for a second phase of data collections

- presentation of findings and recommendations as regards the grading system.

In order to cover those aspects, consultations with UNDP and FAO administrators and Project staff as well as representatives of NGOs/IPs was undertaken. As the project is administered from Islamabad, and the IPs' head offices in many cases are located in Peshawar, the time available for visits to the five regional offices as well as VFUs in the field has proved to be very limited. Still, the planning of the work and design of the study has tried to accommodate those somewhat conflicting interests.

\section{STUDY DESIGN}

The most crucial issue at this particular point in time is the present income earning capacity of the VFU staff, with implications as regards both medium term animal health services sustainability and short term UNDP/FAO/IP financial contributions. Therefore, the data collection of this first mission has focused on that issue. From such an analysis naturally follows an assessment of the VFU grading system.

Most contemporary elaboration and assessments of the functioning of the VFUs and the situation of their staff seems (possibly by definition) to be donor-centred. It seems, however, as if this perspective also has come to greatly influence the key players in the field of providing animal health services, i.e. the local Afghan veterinary expertise.

This study is assessing the situation from a somewhat different perspective - the role of professionals in a civil war environment.

\subsection{Civil War and Animal Health Services}

The overall aim of livestock production is the provision of food for local consumption and cash incomes. Animal health services are means to that end and the producers, given relevant information will individually decide to what extent and at what price level they want to procure them. The VFUs compete for the attention as well as the limited spending capacity of the livestock owners. Moreover, the state of civil war since many years make both customer and provider of services cautious, for many reasons.

In contemporary Afghanistan the VFUs' activities should be assessed in the perspective of opportunistic entrepreneurship possibilities in a war-like environment. In such a situation long-term investments are seldom attractive, sticking it out with a minimum of exposure and a low profile is often a first choice strategy for government staff, private employees and selfemployed alike, even if the local area at the moment is quiet.

Allegiance to outside (international) partners or agencies enhances both economic and physical security for the individual and his family, as does conformity to local power directives. Complementary incomes and devious, perhaps illegal behaviour are tempting for employees, sometimes an absolute necessity for the family survival.

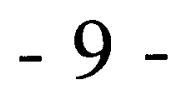


Thus, a study of the VFUs and their staff's income earning capacity should be designed taking those harsh facts into due consideration. Even if at present $9 / 10$ of Afghanistan is not directly affected by skirmishes, FAO and IPs have to understand those strategies for (economic and physical) survival, when embarking upon a VFU privatisation strategy. Still, donor and IP inactivity or complacency during 1996 is not the right approach.

The key player at the VFU is the veterinarian or paravet, responsible for the clinic, who is in a better position than the other employees to work the system to his advantage. The crucial issue from a project objective perspective is: how should the much needed entrepreneurial spirit be encouraged, and how should checks and balances to promote animal health and the interest of the consumer be designed?

This crucial issue relates both to cooperation within the specific VFU and in relations between staff and local farmers and pastoralists, as well as IPs and technical expertise like FAO Project staff and planners. Ideally, the VFU staff, in close cooperation with the expertise close to the "market" for animal health service - i.e. the BVWs - should devise a marketing strategy, in order to adequately promote their services to the farmers and pastoralists. This strategy will adequately take the security aspect into consideration.

From discussions with VFU staff it seems as if such forward planning calls for a change of attitudes among clinic staff in most cases, and a study like this one now undertaken should in itself promote such a change. Also the role of women BVWs in Afghanistan should be assessed in this analysis of value-systems and attitudes. ${ }^{2}$

\subsection{Animal Health Services - A Multi-Faceted Issue}

In many societies, also in Afghanistan the number of livestock defines the social status of the pastorals or farming family in the community. However, the project primarily aims at improving animal health services in order to increase production in the livestock sector, which sometimes might create a goal conflict, also in this Project.

Productive capacity can be assessed from different perspectives:

- the (primarily economic) interest of the owner and his family

- avoiding suffering on the part of the herds and individual animals

- quality of meat for human consumption, locally and nationally

- the export earning possibilities. ${ }^{3}$

The first two aspects is primarily the responsibility of the individual livestock owner, the latter ones are of a public interest, including containment of epidemics, etc. The animal health expertise working with the Project is supposed to contribute as regards all four aspects.

From the point of view of the livestock owner, who at least in theory seeks an optimum quantity and quality as regards off-take, the following services are of interest: ${ }^{10}$

${ }^{10}$ In a recent study" of the Kenyan situation, the most frequently needed veterinary services were clinical examination and treatment, herd health and avisory services, artificial insemination, vaccination and dips. See Spontaneous 
- professional input in case of acute animal sickness

- preventive health care services such as vaccinations

- advice on preventive health activities and feeding strategy

- advice and support as regards expansion and improvement of stock, AI etc.

- advice on marketing opportunities and other economic issues.

From a public interest point of view, the following aspects are important;

- checking of quantity and health of livestock herds in order to assess environmental issues and future production

- meat supply (quality and quantity) and human nutrition situation as well as export possibilities

- reporting on disease outbreaks, containment of epidemics, monitoring of vaccination campaigns.

The survey design and the data analysis as well as the formulation of recommendations will have to take those different perspectives into account.

\subsection{Available Background Data}

Only very sketchy data as regards contemporary rural incomes in Afghanistan in general and veterinary services in particular is available ${ }^{4}$. A study by the project staff of VFU staff incomes in Paktia province in $1995^{11}$ as well as discussion with the Project Management staff has served as the base for designing this test survey. Furthermore, an evaluation of women BVWs as regards transfer of technical skills, work performance and amount of income from the services ${ }^{12}$ provided further background information.

The Project study of a small sample of VFU grade II staff incomes (apart from the fixed monthly salary) reveals, that the veterinarian (DVM) earned 2200 Rs. per month from services whereas the paravets and assistant vets earned Rs. $1500-3100$, depending on how active the individual was in visiting farms. In Khost township (grade III) the assistant vets and paravets typically earned less (Rs. 900 and 1600 , respectively), because they mostly stayed at the clinic, complaining about competition from pharmacies and BVWs. At the grade I VFU studied, paravet income was about Rs. 1300.

The Jalalabad study of women BVWs indicates that the uncertain security situation and the presence of military men hampered the movement of the women and their cooperation with the VFU veterinarian. Incomes varied a lot between different individuals and over the seasons, but typical weekly incomes for those active were in the range of Afs $5000-10000$ (about Rs. 20 - 40).

Private Veterinary Practices Evolved in Kenya Since 1988, FAO 1995

${ }^{11}$ Evaluation Report of the VFUs based on their income in Paktia (Khost, Alishir and Jaji Maidan), by

Dr. Mohibullah Halimi, edited by T.J. Barker, August 1995

12 Evaluation Made on BVW (women), Jalalabad Mission Report by N.F. Gelacio and P. Malakzai, Febr. 1996 
It seems as the VFU staff, with guaranteed remuneration in the range of Rs. $1800-4300$ per month (veterinarian in grade IV and I respectively) and Rs. $1500-2800$ per month compares favourably with other professionals like teachers, who are said to earn about Rs. 1500 , and e.g. qualified drivers (Rs. $2000-2500$ ) or good carpenters (Rs. $4000-5000$ ). If this information is correct and if income earning possibilities are fully exploited it seems as if most VFU staff under present conditions should be in a position to support a family.

\subsection{Survey Design}

This first mission to the Animal Health and Livestock Production Programme project has been undertaken during the period March 7 - 30, complemented by briefing/debriefing visits to FAO Rome. Two visits to meet VFU and project staff at regional offices in Khost and Kandahar have been arranged by the Project Management.

Extensive discussions with Project Management staff have been conducted and meetings were held with UNDP Resident Representative and his staff, the FAO Representative as well as other FAO project staff in Islamabad and in Afghanistan (Annex 3. Persons Met). Discussions have been held with representatives of NGOs/Implementing Partners in the field, and in Peshawar with representatives of four NGOs. Discussions have also been held with the European Union representative in Peshawar and with the Executive Director of ACBAR. ACBAR will play a key role in the second phase of the study survey.

In all, eight VFUs have been visited in the field and during two 2-day workshops with VFU staff conducted by the Project Management, some one hundred animal health staff employed by IPs have filled in a questionnaire re. their own income situation (Annex 5). Facts and personal opinions as well as suggestions put forward by Afghan expertise and expatriate Project personnel serve as the base for assessments and preliminary recommendations.

During this first mission it has not been possible to adequately assess the income of the BVWs. It seems, however, as if incomes vary considerably. There are indications from VFU and Project staff as well as IPs that some by working energetically presently earn a very large extra income from animal health services, primarily vaccinations undertaken in their local community. ${ }^{5}$

The questionnaire should be seen as a complement to the oral communication, and a test of which method to be used for a more comprehensive study conducted by Project staff in cooperation with ACBAR during the second phase.

The first survey touches upon three aspects of individual VFU staff incomè earning capacity:

- the typical income from different services during an intensive and a low activity month, respectively

- the minimum monthly income, i.e. a decent economic base for the employee/family

- what the individual staff can do to enhance his income earning capacity. 
The result of the test survey is satisfactory in that in principle everyone participating in the workshops filled in the questionnaire. A total of 99 VFU staff did that, as follows:

$\begin{array}{cccc} & \text { Khost } & \text { Kandahar } & \text { Total } \\ \text { - veterinarians } & 9 & 3 & 12 \\ \text { - paravets } & 30 & 44 & 74 \\ \text { - assistant vets } & 9 & 4 & 13 \\ \text { TOTAL } & 48 & 51 & 99\end{array}$

Out of the 57 VFUs in the Khost region, 30 were represented at the workshop. From the Kandahar region 27 out of a total of 49 VFUs participated (Annex 2). From a preliminary assessment it seems as if there is a fairly representative sample of VFUs participating in the study, even if staff from some districts were not present because of communication and transport problems.

It seems as if the questions have been easy to understand and not difficult to answer, except for a question on what a minimum decent income would be. Only rarely has a question not been completely answered, but in many cases the questionnaire has been filled in anonymously, which was an option. It is proposed that the questionnaire will be slightly modified and expanded in order to cover aspects pertaining to the revenue and cost situation of the VFUs as such in the full survey (see also 5.5).

The first mission has also assessed if the Project staff can undertake a complementary survey. From this experience and judging from the limited amount of instructions needed to undertake the test survey, it is obvious that Project staff on both national and regional level is fully competent to undertake both data collection and compilation as well as a preliminary analysis of the material. ${ }^{13}$

It has been discussed and agreed upon with ACBAR, that the agency will participate in the next phase of the study by taking the responsibility for distributing and collecting some of the questionnaires. This joint FAO-ACBAR effort is advantageous.

The cooperation will make it possible to collect information also from those NGOs who are engaged in veterinary services but not on a contract with FAO. An opportunity to compare policy and practical outcome of different strategies, e.g. as regards medicine and vaccine pricing policy, privatisation strategy, etc. will be possible.

The second phase of the survey will in principle cover all VFUs, whether under FAO contract or not, and the survey should be conducted as soon as possible. The practical arrangements are the responsibility of Project Management, who should decide on the division of work between Project monitoring staff and ACBAR, to what extent a representative sample should be used, etc.

${ }^{13}$ The data from the survey has been compiled by Mr. Noorulla Atel, and Dr. Basir Ahmad Hashemi and Dr. Abdul Azim Nasseri has contributed valuble translations and interpretations of the answers 


\section{MAIN FINDINGS AND CONCLUSIONS}

The discussions with VFU staff during the workshops have focused on their perceived problems, their present work and income earning situation and their sustainable income earning capacity. Also, the VFU staff have presented suggestions as how to improve the efficiency of their services. Below, those issues will be discussed and finally some tentative conclusions presented.

\subsection{Problems Encountered by VFU Staff}

During the workshops in Khost and Kandahar the VFU staff, totalling about one hundred people (men) had the opportunity to list the problems encountered and come up with suggestions. Below, the main findings of this exercise are presented.

\section{Khost Region}

A. Practical problems related to transport, premises, salary payments, leave, pension and insurance, staff quarters, motorcycles/bikes availability and repair;

B. Availability of medicines and vaccines, poor quality of Iranian and Pakistan medicines and volatile exchange rates, instruments needed;

C. Problem of diagnosing and advising on feeding, a need for laboratory facilities, more study material, competence upgrading and professional support; and

D. Problems related to contact with IP and FAO, earlier urgent proposals neglected.

\section{$\underline{\text { Kandahar Region }}$}

A. Difficulties in securing premises at reasonable costs, clinics are facing transport problems and can't afford motorcycle repair, all BVWs should be given bicycles, need for fuel in winter;

B. Insufficiency of veterinary equipment and medicine, phoney medicines on the market, vaccines and stationary not arriving on time, need for a unified depot;

C. Salaries should be paid on time, salaries for paravets and guards increased, transportation and medicine costs should be covered;

D. There is a need for better diagnostic laboratory facilities, refresher coùrses for paravets, information to schools, propaganda material and loudspeakers, information from IPs and FAO should be timely;

E. A need for better NGO coordination in medicine purchase and disbursement, training in poultry needed, breeding oxen and AI introduced; and

F. Better to work in own district, loan to vets and paravets for procurement of medicine from the market or from NGOs, need to inform Kochies/nomads particularly of services. 
Summing up, it can be concluded that VFU staff are facing a host of practical problems related to their employment by an IP, but grievances and demands are often communicated to the technical support agency, i.e. FAO. Many also feel insecure as regards salary payments, insurance and pensions, and complain about poor working and living conditions many are now living far from their home region.

Furthermore, VFU staff notice that the supply to the local market of medicines often is of low quality, and that pharmacies and BVWs are more adept at securing business than the VFU. Most staff expect the livestock owners to bring the animals to the clinic, and possibly only a minority is determined to work in the field most of the time.

There is a keen interest in the clinic work and a number of concrete proposals as regards further skills development are present: more instruments and better medicines, as well as better planning of vaccination campaigns etc. by their IP and also FAO regional management staff. Proposals as regards the promotion of livestock farming in general and animal feeding and health in. particular are also put forward. There seems to be a true interest in own competence building and advice as regards promotion and marketing of their services.

The VFU staff did not during the Workshops complain about low salaries or salary levels as such, but in a few cases it was mentioned, that the guards also working as BVWs should have a salary increase. Also, in a few cases it was mentioned, that downgrading to grade IV caused problems. This could be an indication of a mounting problem, as IPs in general are not in a position to top up salaries. And if the supply of (free) medicines and vaccines are in the future are not forthcoming (to be charged for by clinic staff) as before, ${ }^{6}$ many clinics and their staff could face serious problems rather soon.

Finally, it should be noted that the VFU staff have a tendency to consider FAO to be their employer, in spite of being employed by an IP. FAO is expected to shoulder the responsibility not only of financing, professional backstopping and technical planning but also of serving as an economic safety-net.

\subsection{Present Income Situation}

In the questionnaire two questions relate to the present income situation of veterinarians, assistant vets and paravets. The VFU staff have indicated their average monthly incomes from different types of services during typical active months and during months with slow business, respectively.

The estimated average monthly incomes during the active and slow months are given in the following table (see also Annex 6).

Table 1. Estimated Total Average Monthly Incomes, Rs.

\begin{tabular}{|c|c|c|c|c|}
\hline & \multicolumn{2}{|c|}{ Active month } & \multicolumn{2}{|c|}{ Slow month } \\
\hline & Khost & Kandahar & Khost & Kandahar \\
\hline Veterinarians & 4828 & 4335 & 3845 & 3977 \\
\hline Assistant vets & 3410 & 3300 & 2786 & 3300 \\
\hline Paravets & $\ldots 2655$ & 2356 & 2812 & 2139 \\
\hline
\end{tabular}


The figures in the table above indicate, that there is no significant difference in income levels between the two regions, even if veterinarians' earnings seem to be somewhat higher in Khost than in Kandahar. One explanation could be the more problematic security situation in Kandahar region.

The variation between slow and active months are not very high either, and the explanation is ${ }^{7}$ that most of the incomes are a salary component, usually making up for at least $90 \%$ of monthly earnings. Complementary incomes are based on sales of medicine, vaccinations and other clinical services (table 2 below).

Table 2. Sources of Incomes in Both Regions, Active Months, Rs.

Veterinarians Assistant vets Paravets

$\begin{array}{lccc}\text { Clinical work, } & 363 & 193 & 93 \\ \text { Sales of medicine, net } & 436 & 337 & 203 \\ \text { Vaccination } & 418 & 195 & 187 \\ \text { Castration } & 109 & 50 & 47 \\ \text { Salary } & 3307 & 2642 & 1927 \\ & & & \\ \text { Total income } & 4632 & 3416 & 2474\end{array}$

If the VFU staff interviewed have given an accurate account of their income situation, they are totally dependent on their salary from the IP, who are to a considerable extent financed by UNDP/FAO. Through the project, a veterinarian in a grade I VFU is paid a salary of Rs. 2500 , plus remuneration for public services of Rs. 1500 and Rs. 300 supervision fee. In grade II, II and IV salaries amount to Rs. 2000,1000 and nil, respectively, but with the same remuneration and supervising fee as in grade $\mathrm{I}$.

Frequency of average incomes during the active months for both regions together, show that the spread of incomes in each professional group is rather narrow. Out of the 15 vets, 5 earned Rs. 4 000-5 000, 4 earned Rs. 3 500-4 000 and only 4 above Rs. 5000.

Amongst assistant vets, typical monthly incomes amount to Rs. 2500 - 3000 (3), Rs. 3000 3500 (4) and Rs. 3500 - 4000 (3), and only two earn Rs. 4000 - 5000 per month. Typical incomes for paravets range from Rs. 2000 - 2500 (23) to $2500-3000$ (30), and as low as Rs. $1500-2000$ (13), and only 5 earn more than Rs.

3000 per month.

Without going into a detailed analysis of the survey at this point in time, e.g. breaking down the data into district and grade levels, it is still possible to draw some valid conclusions as regards the present income level, such as:

- the VFU staff are in all grades totally dependent on salaried incomes from the IP, whether exclusively financed through the Project (UNDP/FAO) or not; 
- the difference as regards total incomes between high activity months and low activity months is almost negligible; and

- because of the low own initiative as regards complementary incomes, the total incomes for e.g. para-veterinarians is not higher than for an experienced local driver, and for a veterinarian possibly in the same range as a good carpenter, who at present in some towns are much sought after.

\subsection{Minimum Income Levels}

The VFU staff also made an estimation as to what average income level was sufficient to survive on for themselves and their family, e.g. a "minimum income level". The answers to such a question (asked by FAO, the technical partner / financier of the project) are by definition extremely difficult to assess, and the data can be interpreted in many different ways. There is obviously always the risk that the respondents in many cases answer the question with the ultimate aim to increase their fixed monthly salary.

It seems from analyzing the answers, as if as many as half of the interviewed persons have misunderstood the question, but those answers that seem to be based on a true understanding of the question (numbering 45) have been compiled in the table below.

Table 3. Minimum Total Incomes, Both Regions, Rs.

Veterinarians Assistant vets Paravets

$\begin{array}{lccr}\text { Clinical work } & 1070 & 596 & 537 \\ \text { Sales of medicine, net } & 1066 & 1225 & 714 \\ \text { Vaccination } & 627 & 608 & 787 \\ \text { Castration } & 315 & 285 & 201 \\ \text { Cash incomes } & 2700 & 3243 & 1646 \\ \text { In kind } & 696 & & 289 \\ \text { Total income } & 6477 & 5957 & 4174\end{array}$

The figures indicate, that the VFU staff in the Khost region indicate a higher minimum level than those working in the Kandahar region; for veterinarians Rs.

7100 compared to Rs. 5400 , for assistant vets Rs. 6000 compared to Rs. 5 300, and for paravets Rs. 4700 compared to Rs. 3300.

According to the answers, the veterinarians on average indicate a minimum income that is Rs. 1845 or $40 \%$ higher than present average for an active month. Corresponding figures for assistant vets are Rs. 2541 or $74 \%$, and for paravets Rs. 1700 , or $70 \%$.

Such an indication of high aspirations is natural and what could be expected. What is clear is, that assistant vets and paravets indicate a need for almost a doubling of their present incomes in order to earn a decent cash monthly income to support their family. Those aspiration, it seems, are rather unrealistic at this point in time, considering the civil war situation and the incomes of other professionals in contemporary Afghan society (see also 5.2). 


\subsection{Enhancing Income Earning Capacity}

The questionnaire poses an open question to the VFU staff as regards their opinion on how to improve on their own income earning capacity in the near future. The answers can be classified in three categories; the general agriculture and farmer situation, what NGOs and donor agencies should do and, finally, specific activities undertaken by animal health service staff themselves.

Many of those interviewed conclude that the war destruction and consequent disruption of rural life often very seriously has affected the situation for the livestock owners. With the collapse of government, the previously free animal health services ceased to function, and restoring veterinary services by way of VFUs has been met with expectations of free public services once again. Both farmers and veterinarian staff harbour such expectations, thus in many cases blocking their own initiative, which is obvious from the answers to the survey.

The veterinarians conclude that the income earning capacity of the farmers must improve and those now living as refugees outside the country encouraged to come back. The farmers should be supported in setting up new ventures like poultry farms. Furthermore, they propose that long term loans are made available also for vets, e.g. for purchase of medicines, to set up complementary farming activities, etc. Incomes will improve if they visit farmers and get to know their situation, better equipment and diagnostic tools, a better supply of good quality medicines and vaccines is advocated.

The assistant vets present a large number of proposals related to how the farmers should be encouraged to increase their livestock herd and incomes, e.g. AI, better animal feed, etc. Furthermore, there is a widespread belief that they have to be more active in the field, working with respect and dignity. Their work can be expanded if they can obtain loans and be assisted in selling medicines.

The paravets present a large number of proposals of a general nature, i.e. activities related to the improvement of farmers' production and incomes, like poultry and bee farms, etc. VFUs continuous contact with farmers, decent prices for services and the supply of quality medicines is crucial, as is advice on issues related to breeding.

Summing up we conclude, that the answers to the question on what an individual staff member can do in many cases only point to the responsibility of someone else than the animal health expert himself; e.g. increased farmer incomes or provision of medicines by NGOs. As many as half of those interviewed only present such solutions to their income earning problems. Still, it comes out clearly from the interviews, that the VFU staff has to work harder, particularly going out in the field to promote animal health issues in general and their own services in particular. A number of very concrete proposals related to complementary VFU staff livelihood have also been presented.

Proposals related to increased staff incomes, based on improvement of the animal health services as such, have also been put forward. Below, some of those specific proposals are listed: 
- supply of medicines and vaccines is crucial, loan for procurement as well as assistance in importing of those is needed;

- IPs and the new regional vet associations should sell medicines through

their own stores accepting credit for purchases;

- basic equipment must be provided, as well as transport (motorcycle, bicycle);

- build our own VFU, better information of services and marketing of competence;

- provide bulls for breeding, incubators for eggs; and

- special information to Kochies/pastoralists on veterinary services.

In general, the establishing of good relations with the farmers is considered a must, as is adequate transport and the supply of medicines. Another issue that stands out is the need for finance, both for investments in complementary means of livelihood and for the purchase of medicines, etc.

\subsection{The Grading System}

An assessment of the present grading system is based on information gathered from VFU staff (see 4.1 above) and from discussions with representatives of IPs, i.e. by an indirect survey method. No direct measurement of the effects of the grading system is feasible. It is envisaged, however, that the second phase survey explicitly will address the issue, and that direct rather than indirect data collection will be utilised. It seems, however, as if it would be of use to the Project evaluation process if some preliminary findings already now are presented, serving as input for further internal discussions.

Criticism of the grading system is forthcoming in the form of complaints to FAO from VFU staff as regards salary levels, lack of funds for transport, repairs and fuel, availability of medicines and vaccines, etc. Those problems and difficulties stem from lack of funds or administrative capacity of the individual IP (their employer) but are often related and referred to FAO to be solved. In that perspective the functioning of the grading system comes under fire.

This situation is a consequences of the automatic downgrading, i.e. the cutting down over a certain period of time of FAO financial support to IPs, who in many cases as it seems have not prepared the VFU staff adequately for this development. Both NGOs and VFU staff seem to expect an economic miracle, pulled off by the Programme Management in the form of a continuous supply of free medicine, transport and housing - - plus adequate monthly salaries.

A grading model of properly phased, gradual lowering of external support to the animal health services on district level has proved suitable, in a political situation going from critical to rather stable, i.e. large scale civil war developing into isolated local skirmishes. For the FAO-IP negotiations in October 1996 and covering 1997 (assuming the Project is extended) the existing grading system without adjustments of criteria and should be maintained, in order not to confuse NGO and VFU staff. 
If the present political situation prevails and does not deteriorate, a medium term strategy of phased privatisation should be implemented. During a second phase 1997-1999, the Project should establish a simplified version of the grading VFUs, in order to enhance the local veterinary staff responsibility. This is necessary in order to attain a sustainable veterinary service on the local level.

A modified grading system should be simple, transparent and robust, serving as a tool to establish a sustainable, privately operated animal health services on the local level. This will imply a different role for FAO (serving as the technical expert) and the NGOs, not any longer functioning as the employer for all VFU staff, but as a partner concentrating on training; coaching and provision of supplies to the VFUs.

\subsection{Conclusions}

The first phase of the mission has tried to secure some first-hand information on the key issues, i.e. the overall operations of the Project, the income earning situation of VFU staff, and the grading system. Below, the main preliminary conclusions are presented (see also Chapter 5).

- The Project is staffed by competent and dedicated professionals, administrators and service staff, going to great lengths to undertake the challenging tasks in spite of difficulties pertaining to communication, uncertainty as regards future finance, the security situation and devastated agriculture lands;

- Implementation of priority aims, i.e. the establishing of VFUs and staffing them with competent expertise, as well as the administrative monitoring of the clinics have been successful, but there is now scope for a more active Project coaching of the VFUs, as only few IPs have the capacity to do that

- The established grading system with four grades has proven effective during the establishment phase and should be retained for the rest of this Project phase, but be modified so as to enhance a true local responsibility, i.e. a privatisation of some clinics;

- Presently, the VFU staff incomes, typically ranging from Rs. 2000 5000 per month are over $90 \%$ made up of salary from the IP, and very little in the form of service charges to the livestock owners. It is assumed, that BVW incomes only amount to a fraction of that, even if in some outstanding cases incomes could to twice that of VFU staff;

- The VFU staff has not during the workshop explicitly (albeit indirectly) complained about their salary levels, and their indication of a need for substantially increased minimum monthly incomes in the interviews should not be interpreted as a requirement to increase FAO contributions to IPs for staff salaries for 1997;

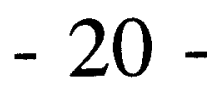


- VFU staff conclude that their income earning capacity will depend on to what extent the farm production in Afghanistan is going back to pre-war levels, if refugees are returning and if rural life is normalised. In the meantime, they point to the need for complementary farming opportunities, both for themselves and in general;

- A number of concrete proposals as regards improved veterinary services are put forward, based on the conviction that they have to improve on the marketing of their services, secure procurement of medicines, arrange transport and obtain loans for expansion of VFU staff activities;

- If an extension of the Project is decided upon, IPs should be contracted for services in 1997, in principle in line with the present grading system, but provisions should be made in the contract for the outright selling of specific VFUs to their key staff during the year;

- There is a need for a modification of the grading system, and it is envisaged, that in the future FAO could provide soft loans or some other means for the privatisation of VFUs, and also contract individual VFUs for public service activities;

- As the Project is entering a new phase in 1997, there is a need for an analysis of the geographical structure of the animal health services, i.e. an assessment if districts are the most rational basis for location of VFUs, or if a new delineation should be considered, i.e. a geographical restructuring of the services should be embarked upon;

- The cooperation between VFUs operating in adjoining districts can be encouraged in order to serve the local market for services in a more cost -efficient way, by joint training, designing of visiting routes to villages and procurement of medicines and complementary inputs in times of high work load (e.g. during Kuchie migrations), etc.;

- It is envisaged, that FAO, in close cooperation with the new regional Veterinary Associations, ACBAR, IPs and individual VFUs in due course will advertise which VFUs are up for privatisation, by way of soft loans or other means, and to be actively assisted and promoted by FAO monitoring staff.

Only those VFUs that have a local base in terms of a certain number of livestock will survive in the long run, but a number of other locations should be serviced in the short and medium term, till a normalisation of rural life and livestock production is attained. When this is accomplished, no one knows for certain.

This two-tier strategy calls for two different grading systems: the established one designed primarily for the establishing a large number of VFUs, which has been highly successful, not the least because of significant man-power and other contributions by IPs and other NGOs, and one condurive to the privatisation of clinics. 
Livestock services have two justifications: public sector needs and private sector demand. It is in the public interest to undertake tasks like disease surveillance, drug and vaccine control, food hygiene/inspection, export inspection and certification and planning for emergency situations. The private livestock owners need services like clinical diagnosis and treatment, supply of drugs and vaccines, AI, production programmes and marketing advice. ${ }^{8}$ The Project will be designed as to secure most of those services, with the help of IPs and Afghan professionals.

As a central government is lacking, FAO has to take on the responsibility to interpret the needs of the public sector, which is done primarily on the regional level, and the demand of livestock owners, which has to be undertaken on the local, i.e. district level. Therefore, one important conclusion is that the animal health veterinary service system should be strengthened on those two levels in particular; dedicated regional Programme staff and VFUs run by committed local Afghan expertise.

Summing up the conclusions reached so far, it seems as if the present grading system, including a low-support grade IV level, is operating well and can be retained also for the contract negotiations in October 1996. The salary levels for VFU staff need not be raised in order to retain competent staff. 


\section{PRELIMINARY RECOMMENDATIONS}

The overall Programme aim is to restore and improve the productive capacity of the livestock. The delivery of basic animal health care services in the districts is the key means in this strategy for a sustainable system. This strategy calls for a true commitment of Afghan veterinary staff on the local level, complemented by external support through NGOs/IPs and UNDP/FAO. It is assumed that the district veterinary system in due course will be operated as private clinics, even if a state veterinary service and livestock production agency eventually are established. In the meantime, FAO will in many respects on the regional level function as an "Official Veterinarian".

The Terms of Reference focus on two issues, i.e. the incomes of animal health service staff, and the grading of VFUs. However, in order to address those issues properly, it is deemed necessary to touch upon a number of other, closely related issues pertaining to the design and eventual extension of the project.

\subsection{General Recommendations}

The project is designed so as to serve both the overall public interest and the needs of the livestock owner. The external input, financed through UNDP, monitored by FAO and implemented by NGOs on the district level, has so far primarily been focusing on the livestock owners. In contemporary Afghanistan, however, the public interest is not manifested in the form of a central government, and to some extent FAO for the moment has taken on that responsibility. Therefore, the recommendations to FAO touch upon both aspects, i.e. the public interest and the livestock owners.

One key task of UNDP/FAO is to assist in resettlement of returning Afghan refugees, promote rural development in general and agriculture output in particular. If this is achieved and the farmers are able to expand their herds, the demand for animal health services will increase. And if such services are made available, livestock output can be increased considerably if there is a local market or export possibilities for the products.

Thus, animal health services should be seen as an investment in increased productive capacity, an investment that international agencies have to finance as both veterinarians and in many cases also some livestock owners presently can't afford - and there is no government to take the responsibility of investing in, providing medicine or vaccine and training of staff or service the local level.

The animal health services on the district level have to achieve sustainable operational status in the medium term, i.e. 2 - 3 years. Thus, it is recommended that the Project is planned to continue for another three years, security permitting. The year 1997 will in this respect serve as a trial year, as regards political (regional) stability and security.

The Afghan livestock owners and local consumers are the prime beneficiaries while the veterinary expertise are the agents of change in this project. Thus, the activities of IPs and FAO - the inputs and organisational forms - should be designed so as to support those agents, 
who should be encouraged to shoulder the burden of professional integrity in difficult times - an ongoing civil war. The year 1997 will show to what extent this can be achieved - and to what extent international development cooperation projects can be effectively and efficiently implemented.

\subsection{Animal Health Expertise - Income Earning Capacity}

Staff of VFUs seems not to be very active at the moment in devising ways and means of securing complementary incomes from services to livestock owners, but rather rely on a fixed monthly salary from the employer. i.e. the IP. Considering the uncertainty of future funding of IPs (by FAO, EU or bilateral donor agencies), this is a risky strategy which has to be modified.

Considering the present civil war situation in Afghanistan, it is not realistic to conclude that the income levels indicated as a necessary monthly minimum by the VFU staff participating in the survey, are realistic, compared for instance to other professionals, both civil servants and self-employed. Therefore, salary levels pertaining to the grading system should not at the moment be increased.

Each VFU should be seen as a profit centre and the staff should ask themselves the following question:

What do the livestock owners need and what is their effective demand, i.e. what can they afford in order to improve on as regards livestock quality and quantity?

The extent to which each VFU, in close cooperation with their BVWs correctly can assess their market for animal health services and meet the local demand will determine the capacity for survival. FAO and IPs have a responsibility to assist them in assessing those issues, finding the key inputs to achieve sustainability, coach them and advise on effective administrative forms, cooperation between clinics, establishing of practices, etc.

In the short term, the following tasks should be supported by IPs and FAO Programme staff in order to enhance a sustainable income earning capacity of the VFUs:

- closer cooperation between VFU and BVWs is a necessity, and methods for assessing local need and demand should be developed, tested and implemented;

- semi-annual VFU action work plans, based on market assessments, should be drafted, revenues and needed inputs estimated and the IP and FAO informed of need for key inputs;

- improve marketing of vet services, i.e. local participation techniques and communication methods ${ }^{9}$, by signboards, pamphlets, over the radio, etc. as well as check lists of cost-benefits of vaccination and treatment for on-the-ground market promotion of animal health;

- advise on and the provision of instruments and good quality medicines and vaccínes;

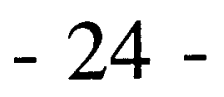


- advise farmers on animal husbandry in general and on animal feed aspects, livestock genetic improvement methods as well as complementary animal production activities such as poultry, beekeeping, aquaculture, etc.;

- provide entrepreneurship management training to VFU key personnel, e.g. through contracting local NGOs, as in the case of earlier support to pharmacies, complemented by expatriate short term expertise;

- use the FAO monitoring staff to consistently convey the message that the responsibility of animal health services rests with the individual VFU and BVW Afghan, complementary technical and monetary support will be provided through IPs; and

- instil the need to get to know the local situation and role of District Shura, the culture, customs and habits, as well as specific problems related to animal husbandry, in order to establish a trusted relationship between clinic staff and farmers and pastoralists.

Summing up we conclude, that the project at all times should encourage the concept of entrepreneurship and small business development, i.e. the establishing of private veterinary clinics, in close cooperation with the Regional Veterinarians and the BVWs. Presently, the Project is not staffed to undertake such skills assessment and capacity building, but complementary resources in the form of additional staff on the regional level for training, coaching and business promotion of VFUs should be considered as from 1997.

\subsection{Attaining District Service Sustainability}

The overall concern of Project Management is the prevailing attitudes of VFU staff and approach of IPs as regards roles, responsibility and continued finance of the project. It seems, as if everyone expects FAO to guarantee "sustainability", i.e. continued payments of salaries, medicines, transport and premises. This is a dangerous illusion.

The NGOs/IPs are temporary agents in the field, whose services are desperately needed under present distorted conditions, but it is the responsibility of the individual professional veterinarian, para-veterinarian, BVWs - to find a way to practice his/her trade, thus earning a living. This calls for a change of attitudes.

In order to achieve the goal of reaching a sustainable district veterinary service in the form of independent VFU practices in the medium term, the following activities should be embarked upon:

- informing the parties concerned (IPs, VFU staff, clients), that the district animal health services in principle will have to be paid from proceeds of the local livestock husbandry, i.e. the farmers and pastoralists themselves;

- the general public interest motivates external support in the form of expert

- technical advice, and to some extent the supply of instruments, medicines and vaccines as well as transport to undertake public service duties related 
to monitoring of the animal health situation, livestock quantity and quality, environmental degradation, etc.;

- the Programme will - through its own expertise and through the IPs, who serve as the sole employer of VFU staff, provide training and advice provide contributions in the form of data collection and animal health monitoring, vaccination campaigns, etc., services which will be paid for as stipulated in management contracts;

- the VFUs will be expected to function as "profit centres", i.e. practices or individual companies, with support from IPs, financed by UNDP/FAO, donors and private agencies. It is the prime responsibility of the IP to encourage entrepreneurship and support the VFU in attaining economic independence and a sustainable organisational set-up;

- FAO should establish a modified model, starting in 1997, as regards support of new VFUs, based on an establishment grant, and in some cases a contractual obligation by VFUs (to be paid for by FAO) to provide data and other information on the local animal health situation, as well as participating in vaccination campaigns, etc.;

- to encourage the private initiative, FAO should provide soft loans or other attractive means to key VFU staff to purchase their clinic, or another clinic or even set up a new one in a priority area. The interest-free loan should be written off in three years time;

- FAO should continue the promotion of private sector medicine supply through "normal" channels, i.e. wholesale imports and retail outlets, veterinary associations in marketing, etc. Advice as regards quality control of medicines and vaccines will be through the Programme Management and the Regional Veterinarians, who for some time should serve as the overseers of the general public interest and be able to advise on the local possibilities of obtaining good quality medicines/vaccines;

- the IPs should be advised by FAO (through monitors, initiators and the proposed business development expertise) on how to undertake training of key VFU staff in management tasks like market surveys and promotion of services, budgeting and bookkeeping, hiring of staff, procurement, etc.;

- FAO monitoring of VFUs should focus on their progress as regards cooperation with BVWs, professional conduct and marketing and performance in the field, and revenue generation;

- VFU staff should be advised on planning instruments, availability of inputs (to be ordered, and paid for), recent R\&D progress, and on methods to improve management of the VFU. IPs should be encouraged/contracted to monitor privatised independent VFUs; and

- the Regional Veterinarians should assess the need for animal health services in all districts, assess the demand for such services and devise a 
strategy for the medium term provision of such services, taking also into account the general public interest as regards meat quality, abattoirs, etc. A plan for establishing sustainable services in the districts should be drafted in a dialogue with IPs operating in the region.

Furthermore, it is envisaged, that the Regional Veterinarians undertake a classification of VFUs in their locations, i.e. the need for animal health services (both as regards the public interest and the perceived demand of livestock owners) and potential income earning capacity in the specific district as defined (see also Chapter 5.5). This serves as a data base for a phased privatisation of VFUs.

Such a comprehensive task is possible to undertake if the Programme will have complementary expertise allocated for planning and monitoring purposes during the next phase, 1997 - 1999. VFU classification will serve as a necessary basis for a modified grading system, as well as for a restructuring of the VFU network, with some clinics not being supported any, longer as the demand from livestock owners is too low and there is no public interest in retaining such services.

\subsection{Grading of VFUs}

Presently, the Programme is operating with four grades as regards VFU financial support from UNDP/FAO. This grading system has served the purpose of explicitly and in a planned way to cut down subsidies, thus preparing the VFUs for privatisation. Therefore, it is recommended that the present system is not changed during 1996 in order not to confuse IPs and VFU staff, but that a simplified grading system is embarked upon if the Programme is extended and contracts for additional VFUs are signed.

Some elements of the present system seem, however, to be counterproductive as regards privatisation, as there at the moment is no positive incentive, neither for individual veterinarians nor for IPs, to abandon the almost total dependency on UNDP/FAO finance. A new, simple and robust grading system should be designed with this objective in mind.

It is tentatively suggested that as from 1997, all contracting of IPs setting up new VFUs should be based on a new two-grade system. A new VFU should sign a management contract with FAO or, till they are operated as independent practice, with a suitable IP. The contract contains an establishment grant and specified services to be undertaken during a certain period. All FAO - IP contracts pertaining to services as from 1997 should include the clause that the VFU can be privatised and contractual obligations will be taken over by the new owner.

It is recommended, that the following criteria are used as a starting-point in the exercise to classify districts/VFUs for the second phase of the Programme starting in 1997:

- need for animal health services, based on the present number of livestock and medium term potential outlook, as well as local demand for animal health services, and the export possibilities;

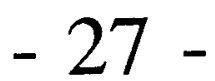


- animal health situation in a public interest perspective, particularly high risk of epidemics, under-nourishment or other health hazards related, e.g. to extensive migration of (pastoralist) herds;

- degree of urbanisation, population density and local meat demand, configuration of district and distances, the political/security situation in the area; and

- degree of economic development in the area, special need for production incentives, restoration after extensive war damage, etc.

The VFUs should be classified into two categories, both as regards the management contract and the establishment grant. The first category comprises those VFUs which already have been supported and also have a reasonably strong base in terms of number of livestock, i.e. the market for animal health services is there to exploit by the VFU unit. Those are not eligible for further grants, but will be contracted for specific services.

The VFUs in the second category (mostly new ones) will for different reasons need support because the density of livestock presently is low, distances are long or travelling difficult, rapid restoration of herds is urgently needed or the animal health situation is precarious. Those VFUs should benefit from the new establishment grant.

There are now a number of VFUs in each region which have been established by IPs with the help of donor finance, in most cases through UNDP/FAO. It is recommended, that those will be informed, that as from 1997 onwards in principle only management contracts for general and specific services will be signed for new VFUs, and the existing grading system used for operations of existing VFUs during 1997 only (see below). As from 1998, well established VFUs can be contracted for general and specific services, but are in principle not eligible for FAO grants.

The establishment grant should be similar for all new VFUs, covering the costs for securing premises, equip the unit with basic medicine, vaccines and instruments as well as a motorcycle and a bike. It should be up to the IP and the individual responsible for the unit to decide on staffing, remuneration and a revenue strategy. For the coming two years, the grant should amount to the equivalent of USD $3000-5000$ per VFU.

The perceived effect of the new model is that IPs will propose the establishing of new VFUs firstly in those areas where the local demand is adequate and there is a good prospect for sustainable animal health services. Secondly, IPs and FAO can agree on the setting up of complementary (temporarily "subsidised") VFUs because they are in the public interest, which entails specific, sometimes tailor-made incentives, which are necessary under civil war conditions perhaps for years to come. In such cases, the management contract will secure the services, in spite of a presently low local demand from livestock owners.

The management service contract between FAO and the VFU/IP for new VFUs should ideally cover a period of two years and promote proper animal health services and the local supply of healthy meat products, as well as the active promotion of livestock husbandry in general. But both existing and new VFUs are eligible for the monetary and professional/management 
support, based on an assessment of work to be undertaken in the public interest (see Chapter 4.6). Such tasks could comprise a dominant share of VFU work over the year, should be specified beforehand and reimbursed accordingly.

As regards contributions from FAO to the specific VFU, those estimates should be based on the criteria listed above. It is recommended that as from 1998, only two categories of VFUs are established, but that the unique local conditions should be taken into account when costs for the planned services are assessed.

The first category of VFUs are located in towns or villages with a relatively large number of livestock in the area, and a promising local market for livestock products. The second category of VFUs are located in more sparsely populated areas, with a low density of livestock and large distances to markets. ${ }^{10}$

The FAO - VFU service contracts, when fully implemented by the Project, should stipulate which tasks to be undertaken (by both parties), the planning, execution, monitoring and reporting of the work as well as the payments. Grants will in principle not be considered. FAO will, through the Regional Veterinarian and his staff provide technical backstopping and undertake training of VFU staff, if complementary resources are forthcoming during 1997.

It is tentatively recommended that the basic VFU services, undertaken in the public interest and paid for by FAO in high and low potential areas, respectively, should be reimbursed according to estimated time and money spent on three different tasks; data collection, standby capacity and monitoring of BVWs. For high potential areas with a large number of livestock the number of work-months is estimated at 5 and 2 for data collecting and monitoring, respectively. For low density areas, the work is more cumbersome and 7 and 3 months will be needed. The average VFU cost for services is estimated at Rs. 4000 per work-month.

The contract for basic VFU services are estimated as follows, for a typical VFU input (annual costs, Rs.):

high potent. low potent

A. General data collection and compilation of the animal health situation in the district

$20000 \quad 28000$

B. Stand-by capacity for assessment of epidemics and vaccinations

$30000 \quad 25000$

C. Monitoring of $\mathrm{BVWs}^{14}$

$8000 \quad 12000$

Total reimbursements

$58000 \quad 65000$

${ }^{14}$ Based on an average of three visits per year to each BVW 
If the staff in ten out of the 16 VFUs now in grade IV would be interested in taking over their clinics, the annual costs for the Project will be Rs. $580000-650$ 000, which is roughly the amount paid during 1996 to the concerned IPs.

The specific VFU services like vaccination campaigns will be contracted out to competent VFUs as need arises. It is envisaged that such extra work can be undertaken by most of the VFUs, sometimes forming composite teams with neighbouring VFUs. In reality this means, that the contracted VFU is paid Rs. 25000 - 30000 per year for procurement of equipment, etc., plus the cost for the actual input, at Rs. 4000 per work-month. More detailed principles for reimbursements should be worked out when the next phase of the Programme is designed.

It is further recommended that in order to encourage a smooth privatisation of the VFUs, it should be tested if key personnel at a number of VFUs already established would be prepared, during the next twelve months, to procure the VFU as an established business venture, i.e. severe the employer-employee situation with his IP. FAO should consider providing such individuals with an interest-free loan (no instalment payments, and reduced by $1 / 3$ per year) based on an evaluation of the clinic, in order to outright purchase the VFU, including equipment, etc.

In reality this means, that FAO is financing the privatisation of the clinics by financing the procurement of them by VFU staff, with no cash payments or bank loans involved. If the entrepreneur sells inventory, motorcycle, etc. or leaves the profession/clinic, he is liable for repayments of outstanding loans. Only in cases like those will FAO (possibly) receive local currency; which should be used for local procurement of vaccines that are provided to other clinics in the region.

The new grading system should be used as a planning tool, i.e. as a means to restructure the animal health services in the medium term.

It is obvious, that the livestock sector in many districts will not be large or economically strong enough to sustain present VFU services. On the other hand, a large proportion of the existing VFUs in certain regions will survive, even if present support from NGOs and FAO is cut out over a period of time. ${ }^{15}$

In the long run, only those VFUs that have a sound economic base in terms of a certain number of livestock will commence to operate, or if, for special reasons in a limited number of cases, there is a specific public need to uphold subsidised animal health services. The Programme strategy should, however, not immediately put undue pressure on the individual VFU staff to buy their clinics, as the alternative for them in many cases could be to leave the profession, convert to being a pharmacist or shop owner, a development possibly detrimental to the delivery of animal health services in that particular district.

${ }^{15}$ Assessment by some NGO representatives put the figure as high as $70 \%$, which seems to be overly optimistic, considering the present security problems 
Therefore, it is proposed that a test covering the 16 VFUs in grade IV is undertaken by Programme Management during a trial period, starting soonest, with the aim to assess if the VFU staff is interested in procuring their clinic. Based on this survey, the future privatisation strategy should be based.

It is important, that the existing grading system is not abandoned till there is a firm commitment as regards the further financing and length of a second phase of the Project. As soon as those issues have been decided upon, however, the new, simplified model of cooperation between FAO and IPs or individual VFUs should be utilised for contracting of animal health services.

\subsection{Design of Complementary Survey 1996}

This first mission has yielded some useful information as regards VFU staff income earning capacity as a basis for the formulation of a consistent privatisation strategy and support of district animal health services. It is recommended that complementary information is gathered in the coming three months, involving the Programme staff on the regional level as well as ACBAR.

The first round of information gathering concentrated on the present income situation of VFU staff. As it is obvious that the one-page questionnaire used served its purpose, it is proposed that the same format is utilised also in the second phase. The survey could be undertaken when workshops are arranged in one of the five regions, or as a specific task by monitors. It is further suggested that a second page with questions related to the costs and revenues of the specific VFU is included, and this should be filled in by all VFUs.

Such an extended survey will give the Project Management crucial complementary information as regards how realistic it is and at what pace to pursue the privatisation of VFUs in different locations. Thus, a complementary page should comprise the following:

- assessment by the person responsible for the specific VFU how large an area the unit should cover, the livestock quantity and present health situation, perceived problems, etc.;

- the potential as regards total work opportunities, estimated monthly income for the VFU, based on different sources of income and minimum staff needs; and

- recurrent costs for operating the clinic.

Furthermore, the Project monitor undertaking the survey in cases when VFU staff is not filling in the questionnaire during a workshop should make a personal assessment of the competence and capacity of the VFU key staff, and their genuine interest in taking over the unit. 26 


\subsection{Role of FAO}

FAO is presently the professional technical agency in the field of livestock production and animal health in Afghanistan. In reality this presupposes a responsibility for information gathering and data collection as regards both public interest in production, environment issues, containment of epidemics, provision of medicines, vaccines and professional services, as well as in meeting the needs of the individual livestock owners.

In this perspective, the monitors and particularly the "Regional Veterinarians" should play a more active role as guardians of the general public interest; animal health situation in general, quantity and quality of livestock herds as well as meat supply to local and national markets, promotion of livestock husbandry, monitoring of vaccination campaigns and technical, administrative and financial support of VFUs, etc.

On the national level, the role of FAO should be the professional competence of last resort, which calls for the establishing of a comprehensive data base. The data base will in due course contain information on district level on, e.g. number of livestock, disease occurrence, medicine utilisation, vaccinations and deworming, ${ }^{27}$ but also on VFU performance, assessment of future livestock productive prospects, etc. This work will take time and the data will not be totally reliable, but the methods and systems for information gathering will be of considerable value to a new national government, in due course being formed.

Emerging veterinary associations ${ }^{26}$ can serve as a good partner to FAO on the regional, but eventually also on the "national" level as regards the promotion of entrepreneurship and management of small scale enterprise, securing of high quality medicines, relevant new methods, planning and promotion of animal health services, etc.

In order for FAO to fulfil this role, it is recommended that the following tasks are undertaken:

- carry through, by way of external consultants and ACBAR, a limited survey of the present economic situation of VFUs and income earning capacity (proposed content, see Annex 7);

- establish over a period of three years a data base for all five regions, built on data collection undertaken by the Regional Veterinarians and their staff and in close cooperation with IPs and other NGOs;

- draft regional plans comprising an assessment of the animal health situation and medium term aims, urgent tasks to be undertaken and the finance of the activities;

- sign management contracts and disperse establishment grants for new VFUs, advertise VFUs for outright sale to professional veterinary staff;

${ }^{26}$ During the project workshops, the Project Management informed VFU staff on the benefits of such organisations, and it seems as if those discussions very rapidly will lead to the forming of regional associations 
- promote entrepreneurship and small business development strategies, both as regards sales of quality medicines and vaccines (wholesalers, importers, pharmacists) and animal health services (BVWs, veterinarians and their colleagues); and

- promote the Regional Veterinarians as provisional "Official Veterinarians". 
ANNEXES

$-34-$ 


\section{AFG/93/004 - Integrated Livestock Programme \\ TERMS OF REFERENCE}

\section{Economist: Income Assessment and VFU Grading}

The Economist Consultart will assist Programme staff by evaluating the existing income level and income potentia! of the stafs of the veterinary field units (VFUs) with the goal to achiove their self-sustainability and ic grade them according to financial viability and thus deremire the optimum levei of y suppon by the proiect and

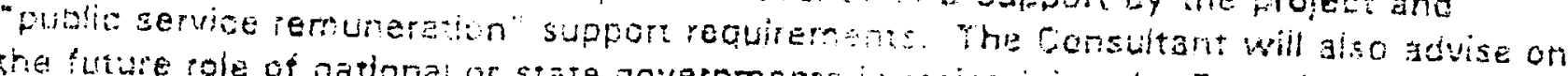

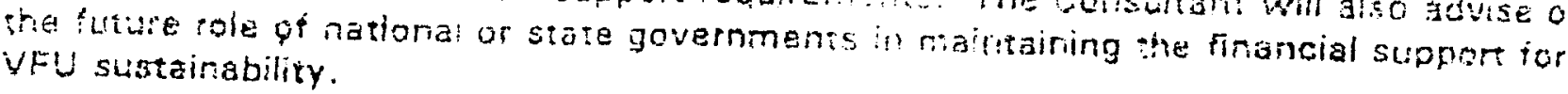

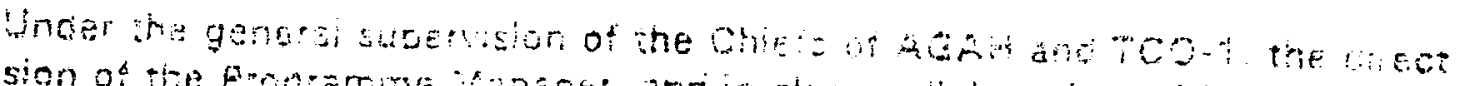

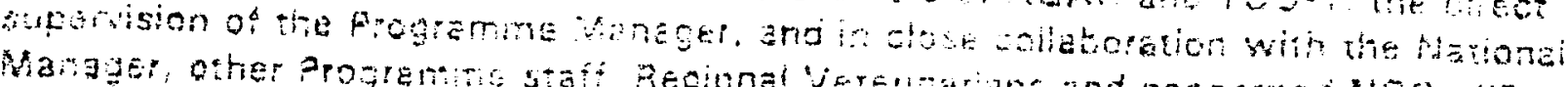

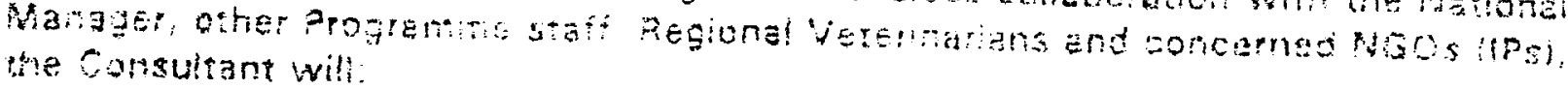
2

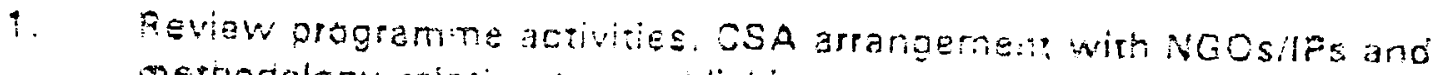

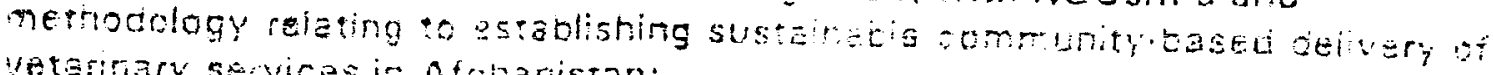
vatanrary savices in Afgtaristan:

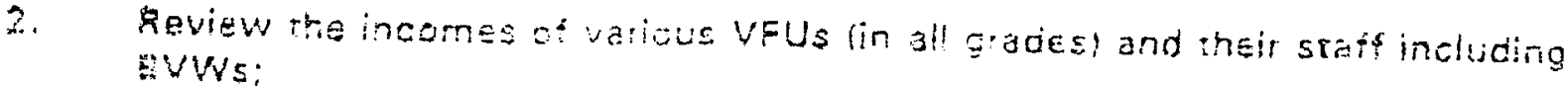

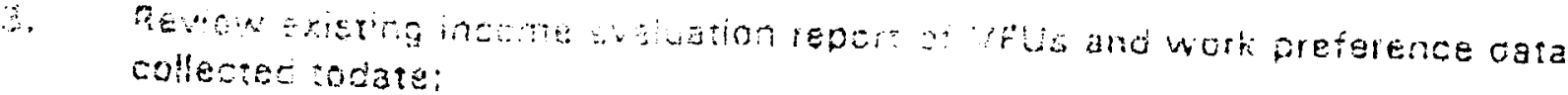

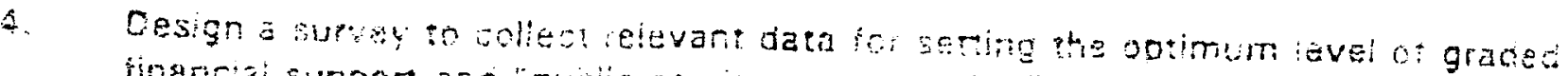

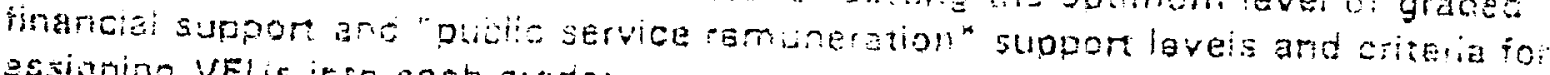
essigning VFlus irito each grade:

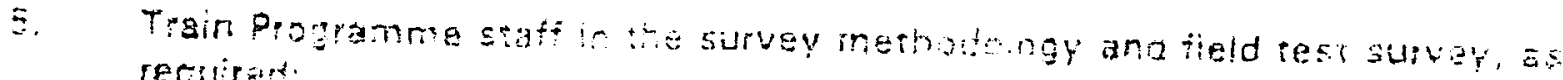
recularet:

H. Prepare a brief ins

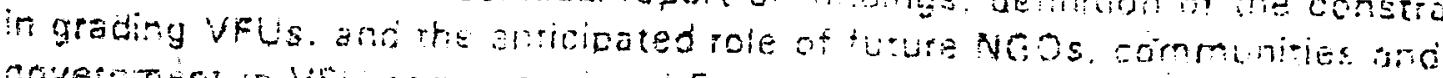

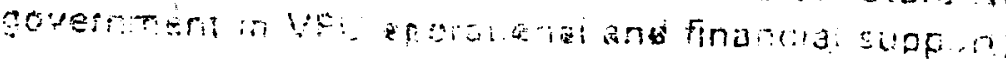

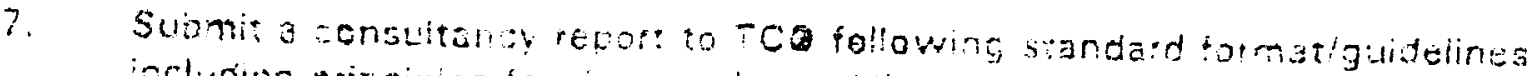

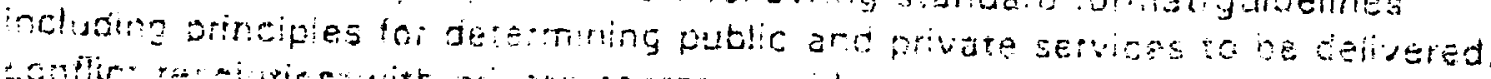

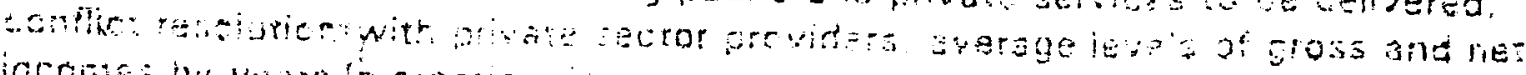

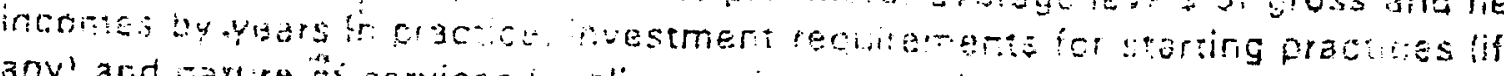

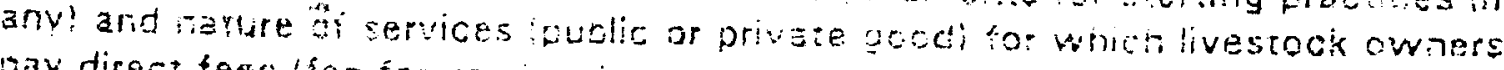
bav direct tees lfee-for-services: 


\section{Second Mission (Ons month in 1996)}

8. Analyze survey data (items 4 and 5) collected by programme staff.

9. Conduct a workshop with Programme staff. NGOs (IPs), community leaders, gic. to review and discuss preliminary findings and recommendations.

10. Prepare a Consultancy Report following standard format/guidelines including pecommendations for grading UFUs according to their financial viability and thus the optimum level of financial support in each grade and "public service remuneration" financiai sippor required cowards self-sustained cperation of VFus, raking into account the outcome of the workshep and comments trom the Frogramme and Headquarers siaff. The report will make recommendacions io scildify the user-pay system and will atso recorrmend c luture VFu pagiamme

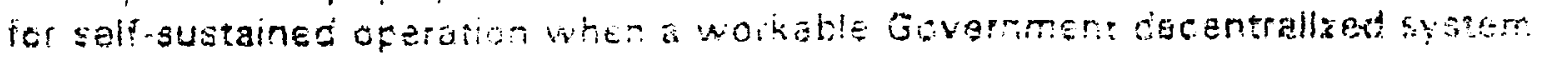
is ir. place.

Distitionions

3

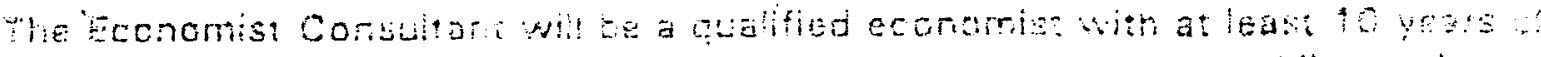

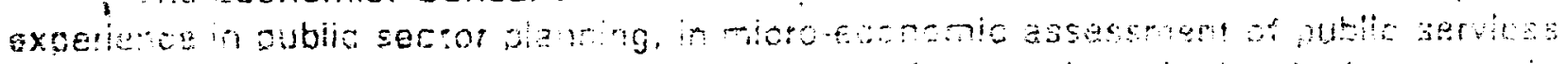

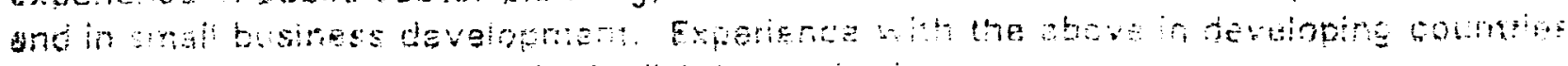

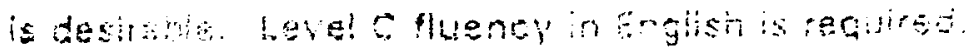

$\sec \operatorname{sintan}^{4}$

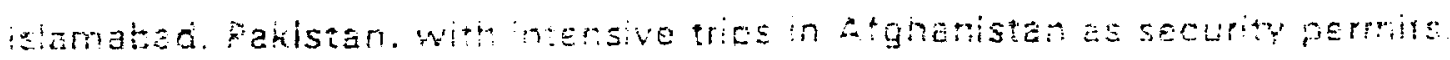

Dutation

Two work months divided inio iwo missions. 
ANNEX 2 - VFU Districts

$-36-$ 


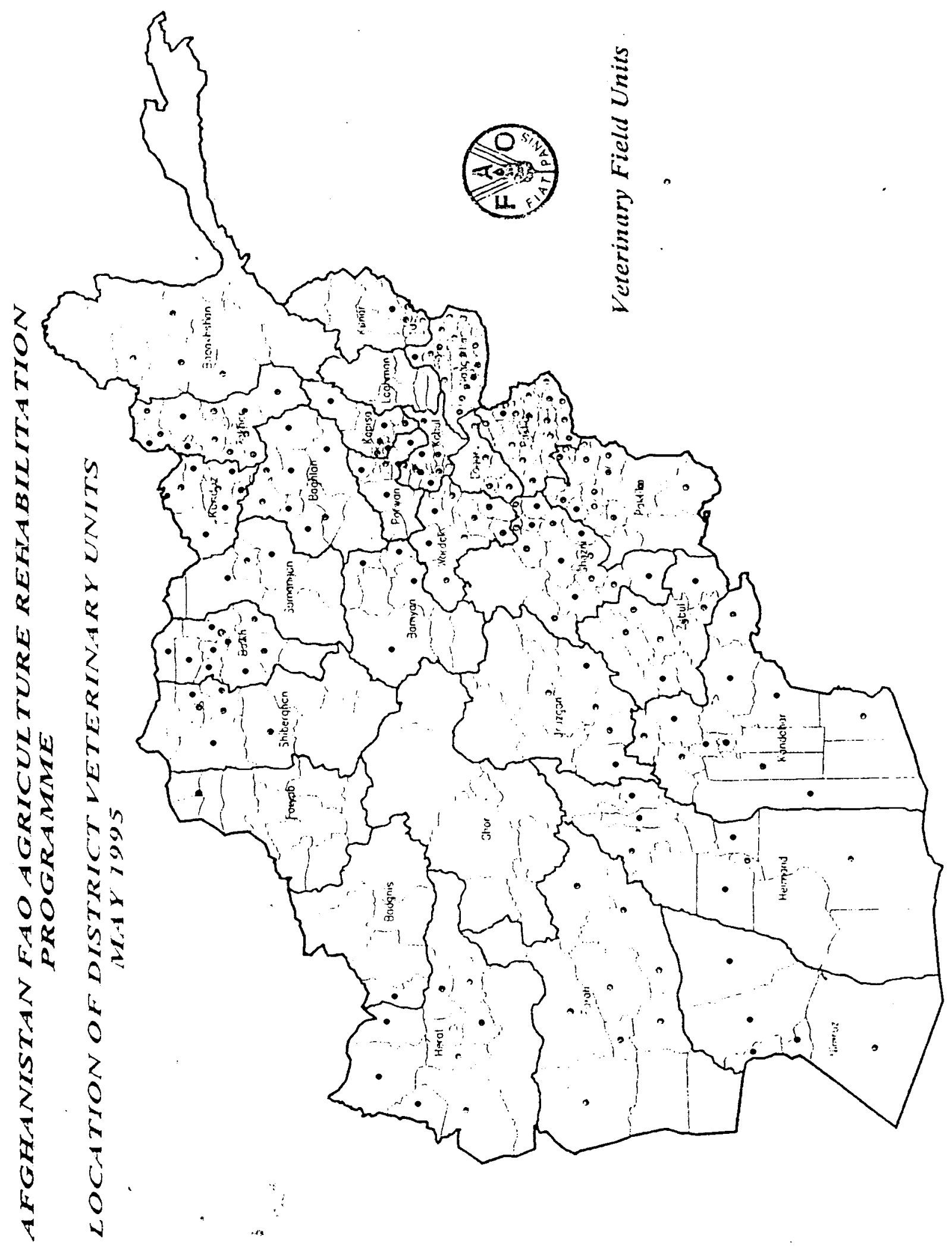




\section{Consultation Workshop/Meeting \\ Participant VFUs}

Khost

\begin{tabular}{|r|l|l|}
\hline No. & Province & VFU \\
\hline 1 & Ghazni & Dehyak \\
\hline 2 & Ghazni & Gilan \\
\hline 3 & Paktia & Alisher \\
\hline 4 & Paktia & Bak \\
\hline 5 & Paktia & Khost \\
\hline 6 & Ghazni & Ab-Band \\
\hline 7 & Ghazni & Nawa \\
\hline 8 & Paktia & Chamkani \\
\hline 9 & Paktia & Gardiz \\
\hline 10 & Paktia & Ismailkhel \\
\hline 11 & Paktia & Jadran \\
\hline 12 & Paktia & Jaji \\
\hline 13 & Paktia & Jaji Maidan \\
\hline 14 & Paktia & Jani Khil \\
\hline 15 & Paktia & Musa Khel \\
\hline 16 & Paktia & Patan \\
\hline 17 & Paktia & Sayed Karam \\
\hline 18 & Paktia & Tani \\
\hline 19 & Paktia & Yaqubi \\
\hline 20 & Paktika & Gomal \\
\hline 21 & Paktika & Katawaz \\
\hline 22 & Paktika & Yahia Khel \\
\hline 23 & Paktika & Yosuf Khel \\
\hline 24 & Paktika & Zeruk \\
\hline 25 & Ghazni & Center \\
\hline 26 & Ghazni & Khwaja Omari \\
\hline 27 & Paktia & Gorbuz \\
\hline 28 & Paktia & Sperah \\
\hline 29 & Paktia & Zurmat \\
\hline 30 & Paktika & Urgun \\
\hline & & \\
\hline
\end{tabular}

\section{Qandahar}

\begin{tabular}{|r|l|l|}
\hline No. & Province & VFU \\
\hline 1 & Helmand & Garmser \\
\hline 2 & Helmand & Greshk \\
\hline 3 & Helmand & Marja \\
\hline 4 & Helmand & Nawa Barakzai \\
\hline 5 & Helmand & Nawzad \\
\hline 6 & Nemroz & Dilaram \\
\hline 7 & Nemroz & Zaranj \\
\hline 8 & Qandahar & Arghandab \\
\hline 9 & Qandahar & Arghistan \\
\hline 10 & Qandahar & Daman \\
\hline 11 & Qandahar & Dand \\
\hline 12 & Qandahar & Khakrez \\
\hline 13 & Qandahar & Maruf \\
\hline 14 & Qandahar & Maywand \\
\hline 15 & Qandahar & Nesh \\
\hline 16 & Qandahar & Panjwai \\
\hline 17 & Qandahar & Shawalikot \\
\hline 18 & Uruzgan & Khas Uruzgan \\
\hline 19 & Uruzgan & Choreh \\
\hline 20 & Uruzgan & Gizab \\
\hline 21 & Zabul & Mizan \\
\hline 22 & Zabul & Qalat \\
\hline 23 & Zabul & Sha Jui \\
\hline 24 & Zabul & Share Safa \\
\hline 25 & Helmand & Kajaḳi \\
\hline 26 & Qandahar & Spin Boldak \\
\hline 27 & Uruzgan & Tarin Kot \\
\hline & & \\
\hline & & \\
\hline & & \\
\hline
\end{tabular}




\section{Consultation Workshop/Meeting \\ Nonparticipant VFUs}

Khost

\begin{tabular}{|r|l|l|}
\hline No. & Province & VFU \\
\hline 1 & Ghazni & Giru \\
\hline 2 & Ghazni & Jaghatu \\
\hline 3 & Ghazni & Moqur \\
\hline 4 & Ghazni & Qarabagh \\
\hline 5 & Ghazni & Zina Khan \\
\hline 6 & Paktia & Dand-wa-patan \\
\hline 7 & Paktia & Gorbaz \\
\hline 8 & Paktia & Jaji-Maidan \\
\hline 9 & Paktia & Musa Khil \\
\hline 10 & Paktia & Nadir Shah Kot \\
\hline 11 & Paktia & Sayed Khil \\
\hline 12 & Paktia & Shamal \\
\hline 13 & Paktika & Barmal \\
\hline 14 & Paktika & Dila \\
\hline 15 & Paktika & Gayan \\
\hline 16 & Paktika & Khirkot \\
\hline 17 & Paktika & Mata Khan \\
\hline 18 & Paktika & Neka \\
\hline 19 & Paktika & Omna \\
\hline 20 & Paktika & Sarawza \\
\hline 21 & Paktika & Serobi \\
\hline 22 & Paktika & Sharan \\
\hline 23 & Paktika & Sultan Khil \\
\hline 24 & Paktika & Wazakhwa \\
\hline 25 & Paktika & Wormamy I \\
\hline 26 & Paktika & Wormamy II \\
\hline 27 & Paktika & Yousf Khil \\
\hline
\end{tabular}

Qandahar

\begin{tabular}{|r|l|l|}
\hline No. & Province & VFU \\
\hline 1 & Bamyan & Panjab \\
\hline 2 & Bamyan & Waras \\
\hline 3 & Bamyan & Yakawlang \\
\hline 4 & Ghazni & Jaghori \\
\hline 5 & Ghazni & Malistan \\
\hline 6 & Ghazni & Nawar \\
\hline 7 & Helmand & Bust \\
\hline 8 & Helmand & Musa Qala \\
\hline 9 & Helmand & Nadiali \\
\hline 10 & Helmand & Sarban Oala \\
\hline 11 & Nemroz & Chakhansur \\
\hline 12 & Nemroz & Char Burjak \\
\hline 13 & Nemroz & Kang \\
\hline 14 & Nemroz & Khash Rod \\
\hline 15 & Uruzgan & Chowreh \\
\hline 16 & Uruzgan & Dehrawod \\
\hline 17 & Uruzgan & Lal-Sarjang \\
\hline 18 & Wardak & Behsud-2 \\
\hline 19 & Zabul & Atghar \\
\hline 20 & Zabul & Shah Jui \\
\hline 21 & Zabul & Shinkai \\
\hline 22 & Zabul & Shmalzai \\
\hline & & \\
\hline & & \\
\hline & & \\
\hline & & \\
\hline & & \\
\hline
\end{tabular}


ANNEX 3 - Persons Met 
$U N D P$

D. Lockwood, Resident Representative

K. Östby, Assistant Resident Representative

U. Davdzai, National Programme Officer

S. A. Aziz, OPS Programme Manager

FAO Rome

H. Konuma, Country Project Officer, TCO

D.E. Ward, Senior Officer, AGAH

A.S. Olofsson, Senior Officer, AGSM

FAO Islamabạd

H.A. Ismet-Hakim, FAO Representative Pakistan

H. Brink, Programme Manager

Project Management

T.J. Barker, Programme Manager

Dr. Abdul Bagi Mehraban

Dr. Abdul Azim Nasseri

Noorulla Atel, Secretary - data expert

Mohammed Amin Rahmani, Acting Regional Veterinarian, Khost Region Amir Mohammed, Regional Veterinarian, Kandahar Region

Basir Ahmad Hashemi, Monitor, Khost Region

Ms. K. Iles, FAO Consultant for AHPIM

T. Thorp, FAO Consultant, Team Leader Programme Review Mission

European Union, Peshawar

E. Macleod, Programme Coordinator, Refugee and Humanitarian Aid for Afghanistan

Non Government Organisations

C. MacFadden, Exeçutive Director, ACBAR

T. Hennecken, Acting Director, Dutch Committee for Afghanistan

C-E Wiberg, Executive Director, and M. Åberg, Finance \& Admin. Director, Swedish Committee for Afghanistan

Dr. Ghafoor Khan and K.V. Freigang, German Afghanistan Foundation

A. Samad, Regional Director of Afghan Development Association

D. Mohd, Coordinator Mercy Corps International

plus more than a hundred $V F U$ staff: veterinarians, assistant vets, paravets and guards/BVWs 
ANNEX 4 - VFU Remuneration 
Remuneration, other than the salaries, is "mostly regarded as being for "public services", e.g. vaccination campaigns, reporting, etc. These payments would normally be paid by government, which is responsible for the public services, and therefore in the future Government could be expected to continue such payments.

\begin{tabular}{|l|c|c|c|c|c|c|c|c|c|c|c|c|c|}
\hline \multicolumn{1}{|c|}{ VFU Staff monthly Public Service Remuneration (PSR) in 1996} \\
\hline & \multicolumn{3}{|c|}{ Grade I } & \multicolumn{3}{|c|}{ Grade II } & \multicolumn{3}{c|}{ Grade III } & \multicolumn{3}{c|}{ Grade IV } \\
\hline & Vet & As vet & PVT & Vet & As Vet & PVT & Vet. & As.Ve & PVT & Vet & As.Vet & PVT \\
\hline $\begin{array}{l}\text { Total (PSR) per } \\
\text { month }\end{array}$ & 4000 & 3500 & 2500 & 3500 & 3000 & 2000 & 2500 & 2000 & 1600 & 1500 & 1500 & 1500 \\
\hline & & & & & & & & & & & & \\
\hline Salary per month & 2,500 & 2.000 & 1.000 & 2.000 & .500 & 500 & 1.000 & 500 & 100 & & 0 & 0 \\
\hline
\end{tabular}

Remuneration for Public service activities

\begin{tabular}{|c|c|c|c|c|c|c|c|c|c|c|c|c|}
\hline 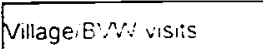 & 1,000 & 1,000 & 1.000 & 1.000 & 1.000 & 1.000 & 1.000 & .000 & 1.000 & 1.000 & 1.000 & 1.000 \\
\hline $\begin{array}{l}\text { Recording \& } \\
\text { Reporting Fee }\end{array}$ & 500 & 500 & 500 & 500 & 500 & 500 & 500 & 500 & 500 & 500 & 500 & 500 \\
\hline $\begin{array}{l}\text { Supervision fee } \\
\text { to be paid to the } \\
\text { VFU leader }\end{array}$ & & 300 & & & 300 & & & 300 & & & 300 & \\
\hline
\end{tabular}

The table above summarizes the levels of the VFU personnel remuneration for public services according to the grades set out at the top. Below is a summary of all major areas of expenditure in each VFU; 'start-up' VFU situations will have greater material and training inputs. Therefore they all tend to reduce with the increase in the self supporting ability of the VFUs.

VFU records and follow-up of the cases treated will be improved during the 1996 CSA. These technical matters are of particular importance and interest to the FAO Project Regional offices and they will be reviewed when visiting the VFUs or during refresher courses for field veterinarians. Rs. 500 per month for reporting and recording fee will be taken out of vets and paravets PSR and will only be paid to VFU staff who maintain their records of animals vaccinated/treated and followed up in a suitable and'acceptable manner 
ANNEX 5 - Test Questionnaire 


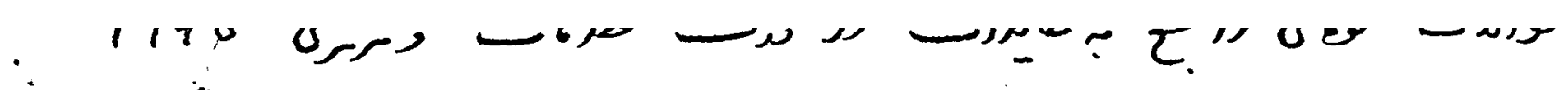

$$
\begin{aligned}
& \text { לק } \\
& \text { : }
\end{aligned}
$$

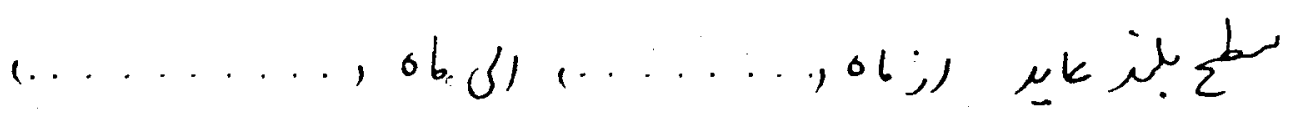

al

:

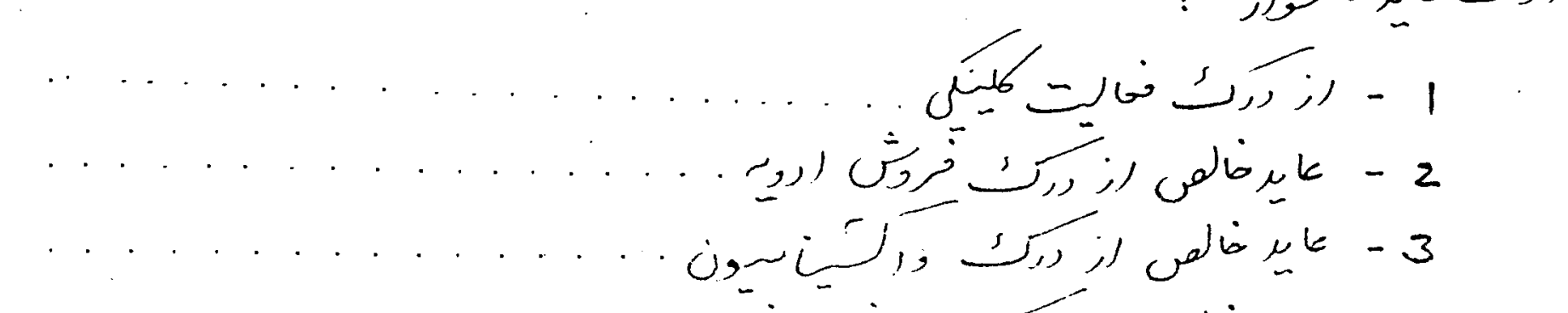

- 4

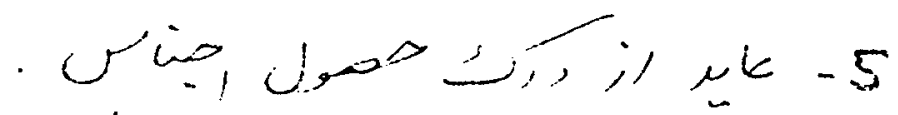

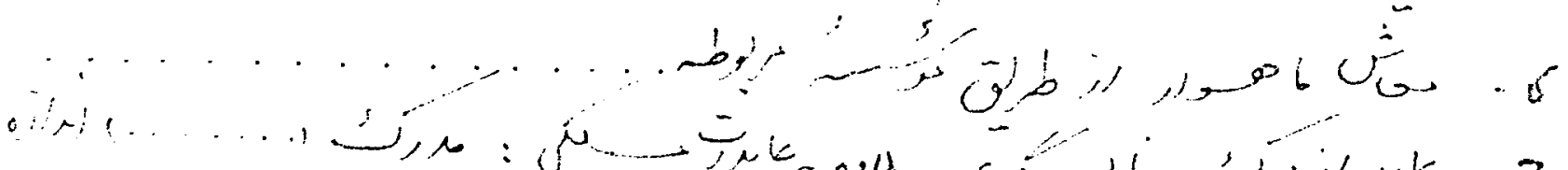

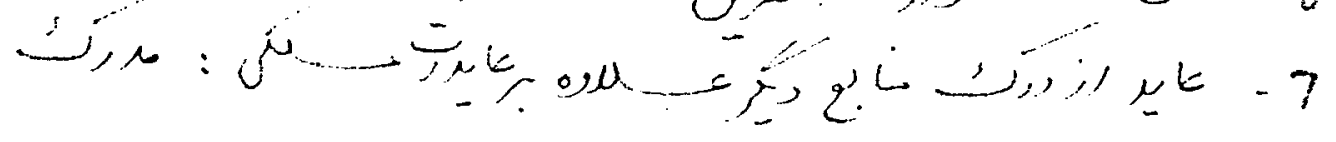

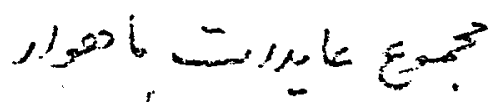

......... o :

L c cris

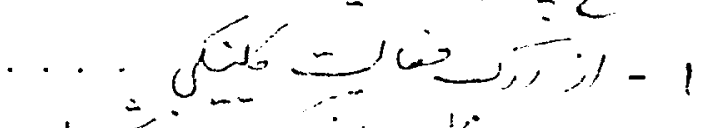

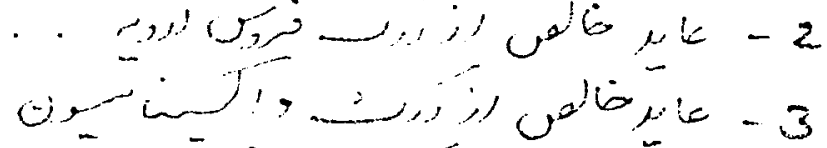

itix

Ui⿱

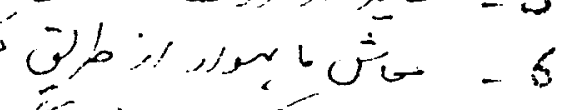

ג :

:

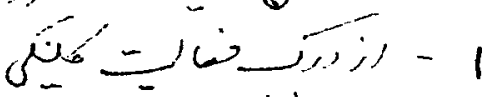

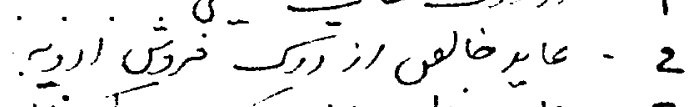

$\dot{0}=1$.

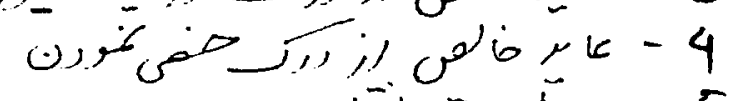

in

rk -6

$\ldots \ldots \ldots \ldots \ldots$. . . . . . . . . .

42

5 w ir ir $i=$ s 
TEST QUESTIONNAIRE

\section{EDUCATION}

POSITION

DISTRICT

PROVINCE

\section{AVERAGE MONTHLY INCOME- INTENSIVE MONTH}

- income from vet services

sales of medicine, net

vaccination

- income in kind

castration

- monthly salary

- income other than vet. services

Total monthly income

2. AVERAGE MONTHLY INCOME- LOW INTENSITY MONTH

- income from vet services

sales of medicine, net

vaccination

- income in kind

castration

- monthly salary

- income other than vet. services

Total monthly income

\section{MINIMUM NECESSARY INCOME PER MONTH}

- income from vet services

sales of medicine, net

vaccination

castration

- income in cash

- income in kind/goods

- income other than vet. services

Total monthly income

4. HOW CAN YOU IMPROVE ON YOUR INCOME EARNING CAPACITY?

NAME

(optional)

43 


\section{ANNEX 6 - Average Monthly Incomes Khost and Kandahar Regions}




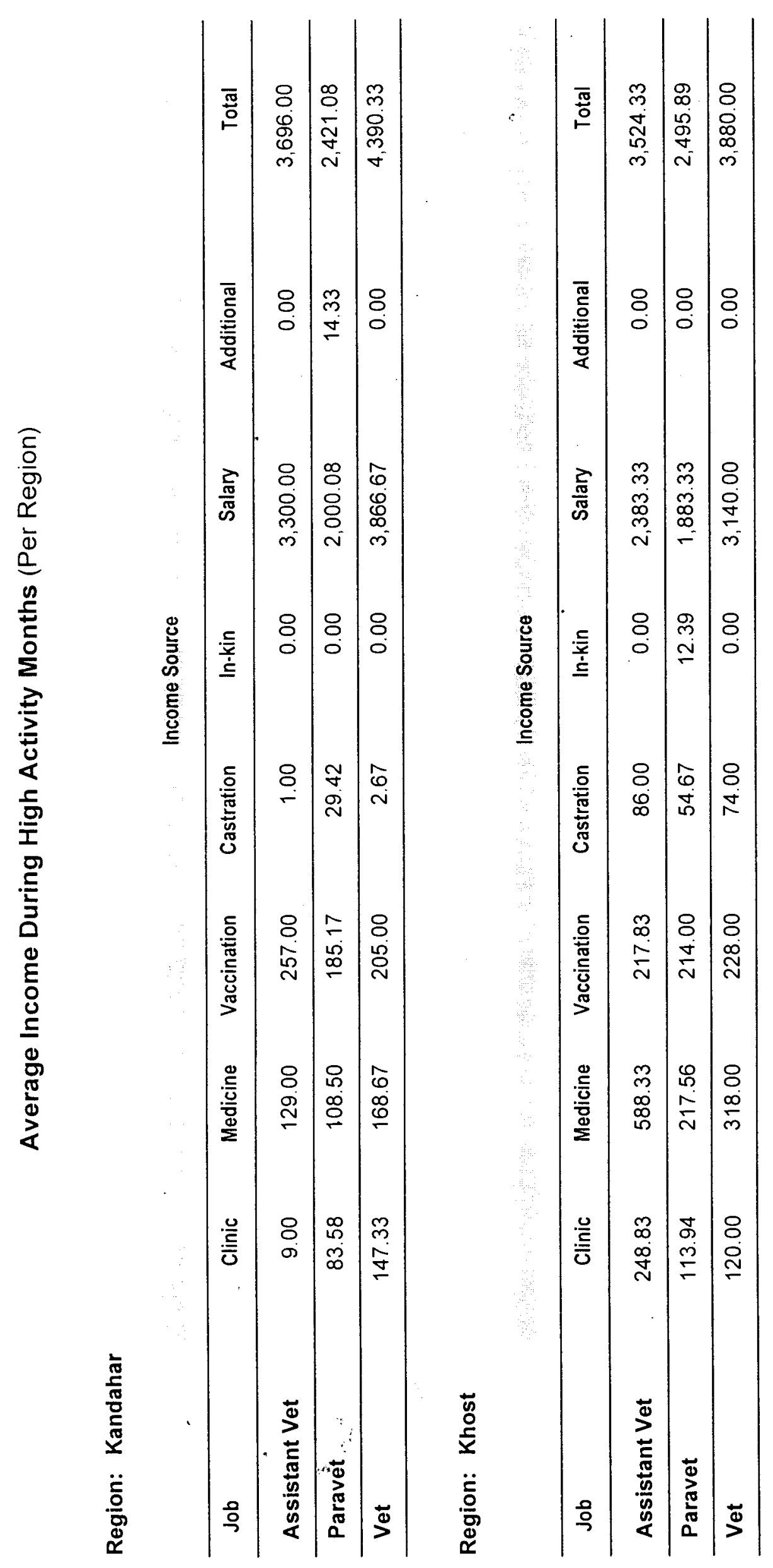




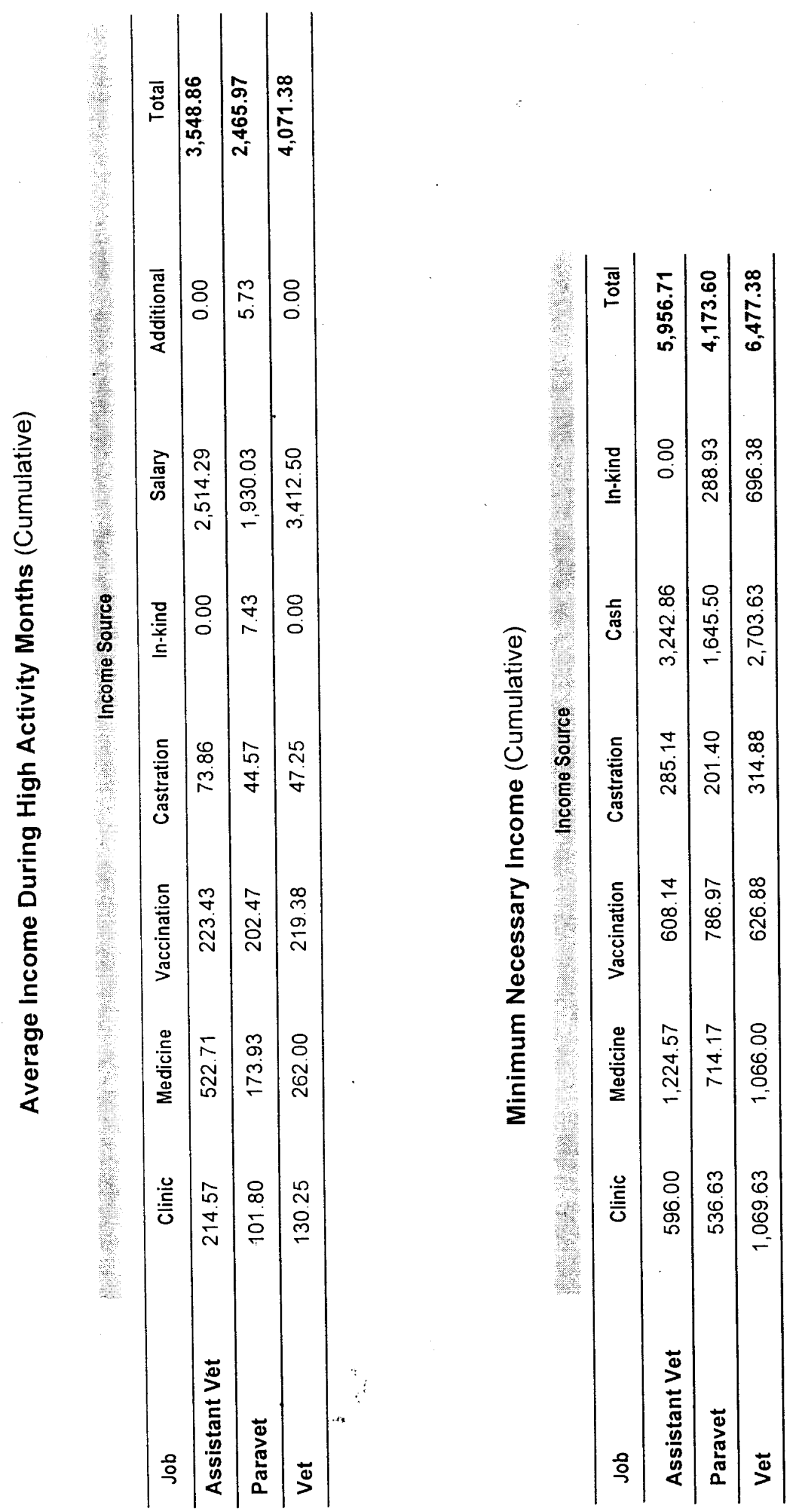




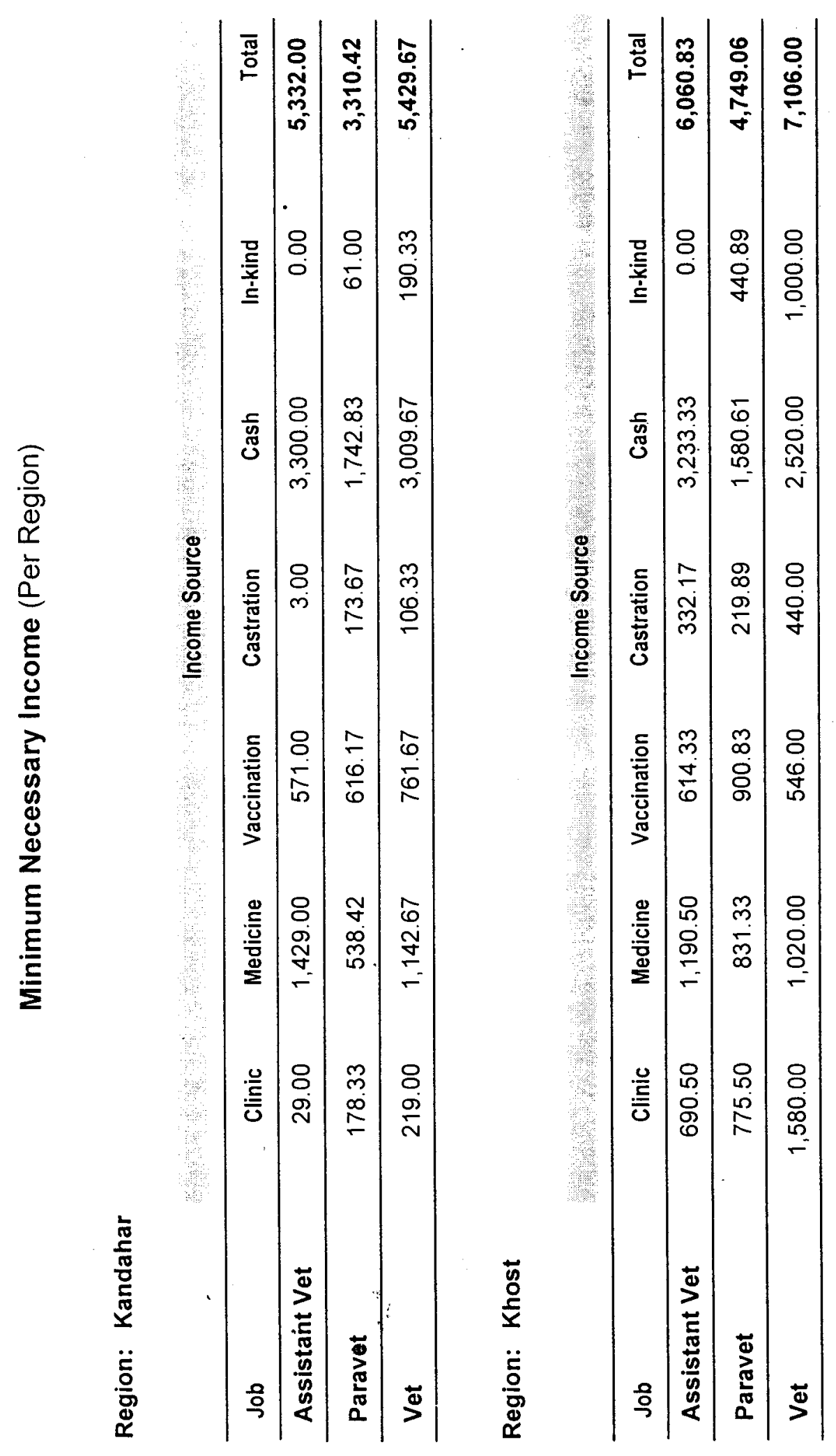


ANNEX 7- Proposed Survey Questionnaire 


\section{Questionnaire 1996}

Animal Health and Livestock Programme

for Afghanistan -- Financial Situation of VFUs

Part A: $\quad$ VFU Staff Income Situation

(to be filled in by each individual VFU staff member)

\begin{tabular}{|c|l|l|l|l|l|l|}
\hline Province & District & \multicolumn{3}{|c|}{ Grade } & Position & Education \\
\hline & & vet & $\begin{array}{l}\text { Asst } \\
\text { vet }\end{array}$ & $\begin{array}{l}\text { Para } \\
\text { vet }\end{array}$ & & \\
\hline
\end{tabular}

Name:

(Optional)

1. Average monthly income of the VFU clinic during high activity period.

From (month)

to (month)

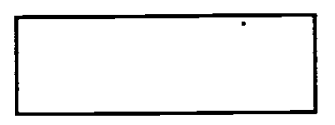

Note: Please fill in only one of the income columns using the currency that is most often used in your district/area.

\begin{tabular}{||l|l|l||}
\hline \multicolumn{1}{|c|}{ Income Source } & \multicolumn{1}{c|}{ Rs } & \multicolumn{1}{c|}{ Afs } \\
\hline Vet Services & & \\
\hline Sale of Medicines (net) & & \\
\hline Vaccinations & & \\
\hline Castrations & & \\
\hline In kind for......... & & \\
\hline Present Salary & & \\
\hline Other than vet services & & \\
\hline
\end{tabular}

2. Average monthly income of VFU clinic during low activity period.

From (month)
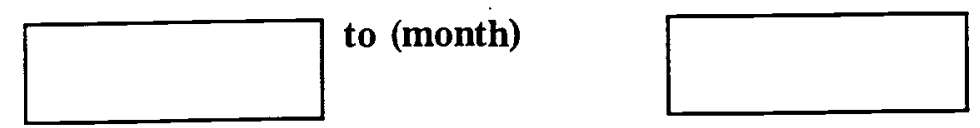

Note: Please fill in only one of the income columns using the currency that is most often used in your district/area. 


\begin{tabular}{||l|l|l||}
\hline \multicolumn{1}{|c|}{ Income Source } & \multicolumn{1}{c|}{ Rs } & \multicolumn{1}{c|}{ Afs } \\
\hline Vet Services & & \\
\hline Sale of Medicines (net) & $\ddots$ & \\
\hline Vaccinations & & \\
\hline Castrations & & \\
\hline In kind for......... & & \\
\hline Present Salary & & \\
\hline Other than vet services & & \\
\hline
\end{tabular}

3. Your minimum necessary income per month (to sustain you and your family).

Note: Please fill in only one of the income columns using the currency that is most commonly used in your district/area.

\begin{tabular}{|l|l|l||}
\hline \multicolumn{1}{|c|}{ Income Source } & \multicolumn{1}{c|}{ Rs } & \multicolumn{1}{c|}{ Afs } \\
\hline General Vet Services & & \\
\hline Sale of Medicines (net) & & \\
\hline Vaccinations & & \\
\hline Castrations & & \\
\hline In kind for......... & & \\
\hline Other than vet services & & \\
\hline Total income & & \\
\hline
\end{tabular}

4. How do you think you can improve your income earning capacity?

a.

b.

d. 
Part B: $\quad$ VFU Operations

(To be filled in by the person responsible for operation of the VFU)

1. What type of livestock is typical in the district?

2. Has the district a high or low potential for raising livestock?

3. Is it usually possible to regularly visit all villages in the district? If not, why?

4. What are the most common treatments of animals in the field? At the clinic?

5. What is now the average monthly revenue for the VFU (vets, paravets and asst. vets) including field treatments but excluding salaries paid from the Implementing Partner: cash income from vet services net income from sales of medicine net income from vaccinations cash income from castrations cash income from other treatments cash income from surgery cash income from obstetrics income in kind / goods other incomes (specify)

6. What are the average monthly costs for running the VFU in terms of: Amount Paid by

total salaries for all staff rent for premises other costs for the premises (specify) travelling (specify) medicines (not charged to customers) costs for other items (specify type) other costs

7. Would it be possible to operate the clinic on revenues from the livestock owners only?...If yes, how? If no, why not?

8. What are the most serious problems facing the VFU?

9. Own suggestions as regards the future operations of the VFU.

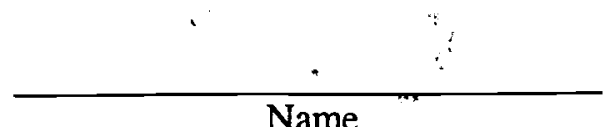


Part C: $\quad$ VFU Summary

(To be filled in by FAO Programme Regional Veterinarian familiar with the VFU and district)

\begin{tabular}{||l|l|l||}
\hline Province & District & Location of VFU Clinic \\
\hline & & \\
\hline
\end{tabular}

Please carefully prepare comments evaluating the situation for each specific VFU and district.

1. In your opinion, does this VFU have a strong base to earn adequate income from the local livestock?

2. Are there special public interest reasons to retain this VFU? If so, what are they.

3. Any other comments relating to this VFU?

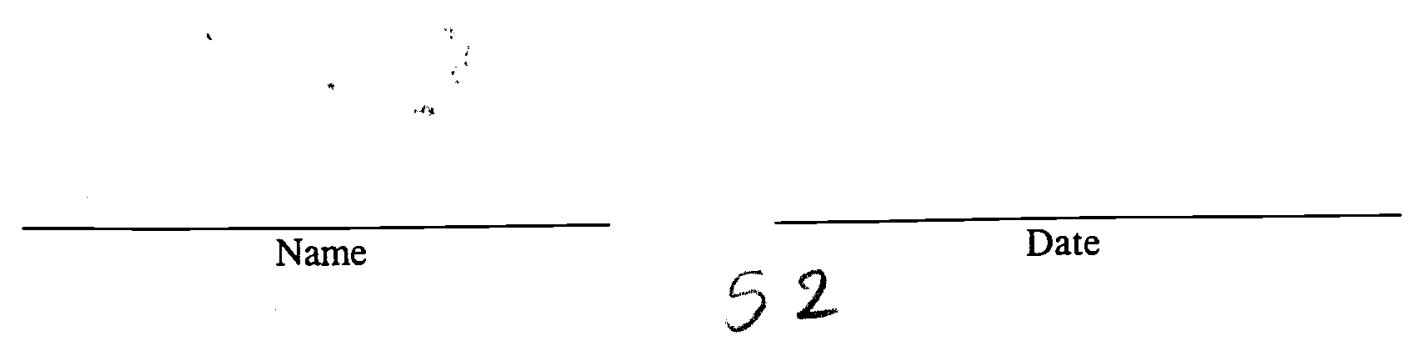




\section{Hezb to continue talks with Kabul govt}

\section{From Rahimullah Yusufzai}

PESHAWAR: The Hezb-i-Islami (Hekmatyar) has decided to continue its talks with the Rabbani regime in a bid to form a broadbased interim government in Kabul.

This decision was taken at the three-day meeting of Hezb-i-Islami central executive and Shura which concluded Wednesday in Jalalabad in eastern Afghanistan. According to a party spokesman Qareebur Rahman Saeed, Hekmatyar briefed the meeting about Hezb-i-Islami's nine-month long talks with the Taliban which failed to produce results and the ongoing negotiations with President Burhanuddin Rabbani's representatives.

Saeed informed that the party executive and Shura unanimously decided to resume talks with Rabbani regime officials next week either in Jalalabad or ,Sarobi. He said it was resolved to take the component parties of the Supreme Coordination Council of Islamic Revolution of Afghanistan (SCCIRA) into confidence about the talks and also try to bring the Taliban and other parties to the negotiation table.

"There has been a lot of progress in negotiations with Rabbani administration. The future talks would focus on giving a practical shape to any agreement on issues like composition of the interim set-up, maintenance of security in Kabul and running of the defence ministry," explained Saeed. He stressed that the interim government would not only involve Hezb-i-Islami and Rabbani's Jamiat-i-Islami but also other parties. He disclosed that certain Afghans aligned with other groups in Jalalabad had agreed to approach the Taliban for joining the interAfghan dialogue. He felt questions like Hekmatyar becoming the prime minister weren't important at this stage.

Saeed made it clear that Hezb-iIslami would in future keep the Jalalabad-Kabul road open and supply electricity to the Afghan capital from the hydel projects controlled by it in Sarobi area irrespective of the fact whether the party was on good terms with Rabbani regime or not. "We have removed all the checkposts on the highway and mobile patrolling has been ordered to stop ha-

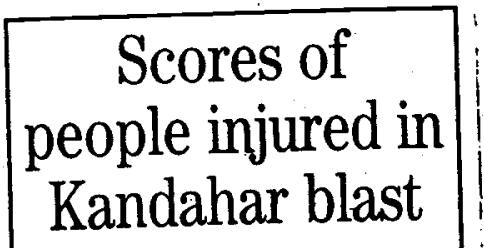

KABUL: Scores of people were injured when an ammunitions dump blast ripped through the southern Afghan city of Kandahar, the Taliban militia's stronghold, sources said Wednesday.

"Many people were wounded, including employees of several non-government organisations, when a huge ammunitions depot in the city centre exploded," a defence ministry official said.

"We don't know what the cause of the explosion was, but it was extremely powerful and we have received information suggesting that that the Taliban suspect sabotage," he added.

With scant news getting out of Kandahar, exact casualty figures, and their severity, were unclear. Sources said though property and vehicles in the area had been seriously damaged.

The Kabul administration, which the Taliban vowed to topple as it besieged the city, said the palace blast was caused accidentally by a diesel heater fire.

However Kabul's rumour mill is still buzzing with stories of conspiracies and sabotage by Taliban spies.-AFP

rassment of passengers on the road. We don't want to contribute to the woes of the people of Kabul," he said.

Meanwhile, Hekmatyar in an interview with BBC Pashto service Wednesday night accused the Taliban of backing out of an agreement of cooperation with SCCIRA after holding talks with them for nine months. He complained that the Taliban.were also threatening his party bases in Paktia province. Hekmatyar said his party would consult the remaining component parties of SCCIRA before concluding any alliance with Rabbani. He argued that Hezbi-Islami wanted an end to the bloodshed in Afghanistan and return to rule of law, political stability and democracy. 